Florida International University FIU Digital Commons

6-12-1998

\title{
Equity policy, educational practice, and limited english proficient (LEP) students in two high schools in Miami
}

Dora Acherman-Chor

Florida International University

DOI: $10.25148 /$ etd.FI13101520

Follow this and additional works at: https://digitalcommons.fiu.edu/etd

Part of the Bilingual, Multilingual, and Multicultural Education Commons

\section{Recommended Citation}

Acherman-Chor, Dora, "Equity policy, educational practice, and limited english proficient (LEP) students in two high schools in Miami" (1998). FIU Electronic Theses and Dissertations. 1086.

https://digitalcommons.fiu.edu/etd/1086 


\title{
FLORIDA INTERNATIONAL UNIVERSITY \\ Miami, Florida
}

\section{EQUITY POLICY, EDUCATIONAL PRACTICE, AND LIMITED ENGLISH PROFICIENT (LEP) STUDENTS IN TWO HIGH SCHOOLS IN MIAMI}

\author{
A thesis submitted in partial satisfaction of the \\ requirements for the degree of \\ MASTER OF ARTS \\ IN \\ COMPARATIVE SOCIOLOGY \\ by
}

Dora Acherman-Chor 


\section{To: Dean Arthur W. Herriott}

College of Arts and Sciences

This thesis, written by Dora Acherman-Chor, and entitled Equity Policy, Educational Practice, and Limited English Proficient (LEP) Students in two Comprehensive High Schools in Miami, having been approved in respect to style and intellectual content, is referred to you for judgement.

We have read this thesis and recommend that it be approved.

$$
\text { Rosa Castro Feinberg }
$$

Alex Stepick

Betty Hegrn Morrow, Major Professor

Date of Defense: June 12, 1998

The thesis of Dora Acherman-Chor is approved.

Dean Arthur W. Herriott

College of Arts and Sciences

Richard L. Campbell

Dean of Graduate Studies

Florida International University, 1998 
(C) Copyright 1998 by Dora Acherman-Chor

All rights reserved 
I dedicate this thesis to my parents, who taught me the love of learning, and to Henrique, Daniel, and Felipe. 


\section{ACKNOWLEDGEMENTS}

I wish to thank the members of my committee for their insightful comments, their patience, and most of all, their support and encouragement. I also want to thank Dr. Carolyn Herrington for her helpful comments and suggestions. 


\author{
ABSTRACT OF THE THESIS \\ EQUITY POLICY, EDUCATIONAL PRACTICE, AND LIMITED ENGLISH \\ PROFICIENT (LEP) STUDENTS IN TWO HIGH SCHOOLS IN MIAMI \\ by
}

Dora Acherman-Chor

Florida International University, 1998

Miami, Florida

Professor Betty Hearn Morrow, Major Professor

Most studies of language minority students' performance focus on students' characteristics. This study uses qualitative methodology to examine instead how educational policies and practices affect the tracking of language minority students who are classified as limited English proficient (LEP). The placement of LEP students in core courses (English, Math, Social Studies, and Science) is seen as resulting from the interaction between school context and student characteristics. The school context includes factors such as equity policy requirements, overcrowding, attitudes regarding immigrants' academic potential, tracking, and testing practices. Interaction among these factors frequently leads to placement in lower track courses. It was found that the absence of formal tracks could be misleading to immigrant students, particularly those with high aspirations who do not understand the implications of the informal tracking system. Findings are discussed in relation to current theoretical explanations for minority student performance. 


\section{TABLE OF CONTENTS}

CHAPTER

PAGE

I. INTRODUCTION

Statement of the Problem

Research Purpose 6

Theoretical Perspective $\quad 7$

Assumptions 9

II. LITERATURE REVIEW

Theoretical Background 11

Theory and Research on Immigrant Minorities and Education 17

The Theoretical Debate on Tracking $\quad 26$

Empirical Research on Tracking $\quad 30$

Tracking and Student Achievement $\quad 30$

Tracking and Segregation $\quad 32$

Tracking, Placement Practices, Ability, and Cultural Capital $\quad 32$

Institutional Effects of Tracking, Detracking and Untracking 34

Research on Assessment of Limited English Proficient Students 36

III. SETTING

The School District $\quad 39$

The School Staff $\quad 45$

IV. METHODOLOGY AND LIMITATIONS 48

$\begin{array}{ll}\text { Procedures and Subjects } & 48\end{array}$

Limitations $\quad 50$

V. RESULTS

Understandable Instruction, Equality of Access to Educational

Opportunity, and Tracking $\quad 52$

Assessment of LEP Students $\quad 60$

Placement: the meaning of the different learning sequences 74

Beating the odds: what does a "high achiever" look like? 85

VI. DISCUSSION AND CONCLUSION

$\begin{array}{lr}\text { ENDNOTES } & 98\end{array}$

LIST OF REFERENCES

$\begin{array}{lr}\text { APPENDIXES } & 121\end{array}$ 


\section{Chapter I Introduction}

"Be kind to honor roll students... You'll probably be working for one of them someday!" (From the Honor Roll page posted at the main office of King Senior High School) "If ability grouping persists because educators and the lay public believe that it is a rational mechanism for sorting and selecting students for positions on the basis of talent, then those students who rise to the top groups should be treated by educators and the public as if they were superior, regardless of their actual skills and competencies." (Pallas et al., 1994).

\section{Statement of the Problem}

Despite the official discourse stressing equality of educational opportunity in the public schools, both immigrant and native-born minority students ${ }^{1}$ continue to be disproportionately represented in the lower track courses of American high schools (Gamoran and Berends 1987; Oakes 1982; Steinberg, Brown, and Dornbusch 1996). Poor and minority students tend to have lower achievement and attainment than white middle class students (Oakes 1985). Black and Hispanic high school students are also more likely to drop out than their white peers (National Center for Education Statistics 1996b: indicator 5). As a result, white high school graduates are more likely to be enrolled in college than their Black and Hispanic counterparts (National Center for Education Statistics 1996b:indicator 8). ${ }^{2}$ Since educational qualifications are inextricably connected to occupational status (Collins 1979; Jencks et al. 1979; Weber 1946), these disparities in educational achievement, attainment, drop out rates and access to higher education reflect a disparity in opportunities for social mobility. All of 
the above is particularly problematic for immigrant minorities who face the hardships associated with moving to "the Land of Opportunity" with the dream of social mobility for their offspring.

Both our everyday perceptions and the official discourse present education as a meritocratic system where students are placed in classes appropriate to their ability and motivation (McLaren 1998:214). Research, however, has repeatedly pointed to the persistence of the correlation between minority status (both in terms of socio-economic status and in terms of ethnicity), placement in lower track courses, and lower educational achievement and attainment (Hurn 1993; McLaren 1998; Oakes 1982; Steinberg, Brown and Dornbusch 1996).

Education is an important element in immigrants' perceptions of their opportunities in America. In fact, the perception that public education offers quality education and equal opportunity is one of the reasons many immigrants come to this country (Portes and Rumbaut 1996). In 1990, advocates for Florida's language minority immigrants sued the State Board of Education in an effort to improve Limited English Proficient (LEP) students' access to educational opportunities. Their demands for equality of access to educational opportunity resulted in an agreement between several advocacy groups and the Florida Department of Education, dictating policies that require schools to provide understandable instruction. The agreement, usually referred to as the Consent Decree, also requires efforts to ensure that language limitations do not prevent students from receiving challenging, quality instruction (LULAC et. al. v. Florida Board of Education and Florida Department of Education 1990). 
In general, Miami-Dade County high schools ${ }^{3}$ offer two types of diploma: the Standard Diploma and the Superintendent's Diploma of Distinction. ${ }^{4}$ The latter indicates a higher level of academic achievement and the completion of community service. The addition of a self-adhesive seal to one of these two diplomas indicates a College Ready Diploma and/ or a Vocational Ready Diploma. There are different criteria required for each of these diplomas, regarding either the student's GPA (Grade Point Average) or a specific Program of Study, as shown in Appendix 1. Despite these options, within these neighborhood schools there are no formal vocational or academic tracks that would automatically exclude students from college education, as is the case in Germany, England or Japan (Brint 1998:43). On the other hand, the sequences of courses that students take can exclude them from being accepted into a four year college, forcing students to spend a year or more doing remedial work at the community colleges.

The official policy asserts that students, with the help of teachers and guidance counselors, choose the courses that are most appropriate for their ability and motivation levels (Miami-Dade County Public Schools 1996b). Students are placed in courses offered at different levels (regular, honors or Advanced Placement) in all four major content areas (English, Math, Science and Social Studies)(Miami-Dade County Public Schools 1997a). In addition to these levels, in math and science students can follow different sequences. Some sequences are "accelerated" leading to College level Advanced Placement courses in the junior and senior years, while others are limited to basic notions of the subjects and are considered less challenging. A $9^{\text {th }}$ grader can follow a sequence of Algebra I taken in two years, (parts A and B), followed by Informal Geometry, and thus have the three math credits required for graduation. Other students 
might take a sequence of Algebra I, Geometry and Algebra II (regular or honors) and take a fourth advanced course before applying to college. Most successful students already enter high school having taken Algebra I, Geometry, and some students have even completed Algebra II. Those students can finish high school with college level courses such as Calculus and Statistics already completed. In science, college bound students follow a sequence that includes Physics and Chemistry leading to Advanced Placement (A.P.) classes. Others are placed in non-sequential science classes (Environmental Science, Earth and Space Science, Marine Biology, Ecology) that give them the three science credits required for graduation and a very basic knowledge of science. Florida State universities also require two years of study of a foreign language that is not a requirement for high school graduation.

As a result of these initial placements into different sequences, which many times start at middle schools, students finish high school with highly differentiated academic "credentials." This practice is not exclusive to Florida. According to a 1996 study by the National Center for Educational Statistics (1996a), the majority of schools nationwide offered different levels of math and science courses for students at the same grade level. In 1994 all minority groups had smaller percentages of high school students taking more advanced math and science courses than the percentages of whites taking these courses (National Center for Education Statistics 1996a: Table 29-2). Despite the dispositions in the Consent Decree regarding equal access to educational opportunities to LEP students, Florida minority students follow the same pattern of the rest of the country. They continue to be under represented in the courses belonging to the more challenging and prestigious learning sequences, the advanced level courses ${ }^{5}$ as shown in Appendix 2. 
Miami-Dade County Public Schools (M-DCPS) is the fourth largest school district in the country (Miami-Dade County Public Schools 1998b). It is also among the districts with a high percentage of minority students, both foreign born and native, who are of Limited English Proficiency (LEP). Districtwide, 16 percent of the districts' students are LEP: 22.4 percent in elementary school, 8.5 percent in middle school and 10.2 percent in high school (Miami-Dade County Public Schools 1996a: xvi-xix). Both of the schools in this study have higher percentages of LEP students than the district average for senior high schools: 25 percent and 18.9 percent. (Miami-Dade County Public Schools 1997c). Since the typical LEP student spends an average of three years in ESOL (English for Speakers of Other Languages) programs (Fleischman and Hopstock 1993), these high percentages of LEP students in high school indicate recent arrival, with students entering M-DCPS at middle or high school levels.

This research is part of a larger project called "The Academic Orientation of Native-born and Immigrant Minority Adolescents" directed by Alex Stepick and Carol Dutton Stepick (1995). The project includes quantitative and qualitative research involving six immigrant-ethnic minorities (African-Americans, Haitians, West Indians, Cubans, Nicaraguans and Mexicans) in four different Miami Dade county high schools. ${ }^{6}$ This study only deals with two of those four schools.

The project investigates three components that are believed to influence students' academic orientation, either through their cultural orientation or through their academic achievement. The first component deals with students' social capital, that is, issues of gender, family, peers, and community. The second component deals with issues of school policies and practices. It includes school-community relations, school 
characteristics, and educational policy. ${ }^{7}$ This study is based on research that addresses this component of the project. The third component of the project deals with contextual and individual variables such as neighborhood, economic opportunities, immigration status, and number of years in the U.S (Stepick 1995). While the other researchers in the project focused on the students and their families, this paper reports on the part of the research that deals directly with the schools, tracking practices, and the implementation of educational policies that concern minorities' right to equal access to educational opportunities.

\section{Research Purpose}

The purpose of this thesis is to better understand how the school context in general, and tracking practices in particular, affect the implementation of policies demanding equality of access to educational opportunity for language minority students. The thesis examines how policies aimed at guaranteeing equality of educational opportunity, such as the Consent Decree, interact with the school context. School context includes school organizational processes, such as tracking and testing practices, as well as other school characteristics, such as overcrowding, limited resources and attitudes towards immigrants. Qualitative methodology in general, and participant observation in particular, offer a unique contribution to the understanding of the interaction between student characteristics, school context, and the implementation of educational policies. Through the analysis of the interaction between LEP student characteristics and school organizational processes, the study hopes to shed light on 
important constraints faced by two M-DCPS high schools in guaranteeing equality of access to educational opportunity as required by law.

\section{Theoretical Perspective}

Sociology of education has yielded two main paradigms, one from the functionalist perspective, and one from the conflict perspective, dealing with the role of schooling in modern society and which influence how sociologists and anthropologists address the question of differential achievement. The functionalist tradition attributes differential achievement to variables mostly outside of the school system, affirming the neutrality of schools. In contrast, the conflict tradition frequently argues that ability grouping and tracking are important mechanisms in the maintenance of differential achicvement.

The empirical research conceming minority achievement (both minority in general as well as language minority) focuses primarily on the question of why so many fail. For sociologists the primary variables are social variables, such as parents' cducation, socio-cconomic background, and social capital. Anthropologists are more inclined to look at the differences between school culture and the child's culture, along with the nature of the adaptation strategies of minority groups. Such studies of adaptation strategies of minorities to schooling frequently mention their attitudes toward schooling (academic oricntation) or teachers' perceptions of minorities as important elements in minority failure.

Most studies in sociology of education have come under criticism for staying at the level of macro-sociological structural variables and ignoring what actually happens 
inside schools (Karabel and Halsey 1977). These studies reinforce the myth of democratic schooling, which portrays schools as places where equality of opportunity is taken for granted, implying that the individual has control over his success or failure in the educational system (McLaren 1998:214-216). On the other hand, studies in anthropology of education have been criticized for their phenomenological approach and for ignoring structural determinants such as class, gender and race (Apple and Weis 1986). This study attempts to overcome these limitations by using a model that looks at the interaction between student characteristics and school organizational processes, particularly tracking, and other constraints both structural and ideological. This approach allows for an examination of the intersection between policy as a reflection of structure (both economic infrastructure and political-ideological super structure) and human agency.

Policy is ideology in the sense that goals are worded in ways that reflect what policy makers believe is important to say. The extent to which policy is actually implemented in specific districts and within the districts, in each individual school, reflects the beliefs and needs of the people who are responsible for making these policies reality. This includes policy makers themselves, who may allow loopholes in the policy that undermine it, mid-level district staff responsible for supervising implementation and front line policy-makers/implementers, the actual people in the schools: principals, counselors, teachers. Inevitably, there is a process of interpretation in the application of the policies, involving both ideological as well as practical elements. 


\section{Assumptions}

Although educational policy is always cushioned in a discourse emphasizing equality of opportunity and education as an agent of social mobility, the failure of so many minority and lower SES students in public schools points to a reality of social reproduction. "Social reproduction refers to the inter-generational reproduction of social class," in other words, "working class students become working class adults, and middle class students become middle-class adults" (McLaren 1998:189). This paper adopts the perspective proposed by George and Louise Spindler (1987), Ray McDermott (1987), and Henry Trueba (1987b), that failure is socially constructed and not necessarily an inherent part of every society. How do people such as guidance counselors, who are supposed to help students, become "gatekeepers," agents of social reproduction? To address this question, this study does intensive interviewing and participant observation with teachers and counselors, those who are directly involved in the process of placing students in different course levels.

Through the analysis of the interaction between LEP student characteristics and school organizational processes, the project aims to shed light on the constraints faced by two M-DCPS high schools in implementing policies guaranteeing equality of access to educational opportunity. The paper identifies both structural and ideological constraints at the schools' organizational level in achieving the goals of said educational policies. ${ }^{8}$ In addition to focusing on tracking practices as an obstacle to equality of access to educational opportunity, the paper also points to other structural constraints. Those include lack of appropriate funding for sufficient counselors, teachers and classrooms, resulting in overcrowding, and insufficient time assigned for teachers to 
perform the duties required by policies, such as committee meetings. Ideological constraints include the perceptions about immigrant groups held by school personnel responsible for student placement, such as guidance counselors and teachers. Yet other influences come from the way specific populations perceive and relate to policies and practices: how the immigrant population perceives and reacts to the school and its practices.

In sum, this paper argues that immigrant students' placement, and consequently their achievement and attainment, which affect their opportunities for social mobility, are influenced by factors related to the school environment as much as they are influenced by student characteristics. 


\section{Chapter II Literature Review}

\section{Theoretical Background}

Both sociologists and anthropologists of education struggle with the question of why certain groups are frequently over-represented in certain tracks. While sociologists, with some exceptions (Oakes 1986), are mostly concerned with issues related to social class (Bowles and Gintis 1976), anthropologists have focused more on the effects of cultural issues on the academic orientation and achievement of ethnic and racial minorities (DeVos 1980; Gibson 1997; Ogbu 1974). Both strive to explain why differential achievement by class and ethnicity has persisted in public education.

Two main theoretical currents have addressed this problem. The first tradition, coming from a functional paradigm, views schools as agents of social mobility. The tradition affirms the neutrality of public schools, defining schools "as a democratic institution that functions to improve the social position of all students - including, if not especially, those groups that are subordinated to the system" (McLaren 1998:190).

The second tradition emphasizes public schools as agents of social reproduction. According to some reproduction theorists, schools reward the cultural capital of the hegemonic class with academic success and deny legitimacy to the types of knowledge of other classes (Bourdieu and Passeron 1977; Kalmijn and Kraaykamp 1996). Yet according to others, schools emphasize different skills and attitudes for children from different backgrounds, teaching children the attitudes "appropriate" to their class position in the job market (Bowles and Gintis 1976; McLaren 1998; Willis 1981).

Recently, a third view posed by Saha (1987) suggests that schools actually fit both models, in that reproduction and mobility are two faces of the same coin, based on 
the fact that social mobility for individuals is different from group mobility. According to this view schools offer the possibility of mobility to specific individuals, but schooling does not offer the possibility of mobility to the working class as a whole. Mobility is offered as an option to individual members of non-dominant groups, whether they are working class majority or ethnic minority, without altering the structure of domination. Success stories of specific individuals within the educational system serve to reinforce the belief in a meritocracy, while social reproduction is the rule for the majority of the students. Enough succeed to reinforce belief in the neutrality of public schools, perceiving them as places where the allocation of educational resources and the distribution of opportunities to learn (Stevenson, Schiller, and Schneider 1994) are done on the basis of objective criteria. It is in this context that research on tracking as a mechanism of gatekeeping appears, stating that under the cloak of separating students by ability to better serve their needs schools are actually segregating students by class and ethnicity and differentially distributing access to valuable cultural capital.

Saha's theory is congruous with ideas first posed by Gaetano Mosca (1939) regarding the circulation of elites. In this case, schooling and the ideas of meritocracy are modern democratic nations' equivalent to Mosca's "political formula"; a "great superstition" or "universal illusion" that everybody believes in, including the ruling class (Mosca 1939). Interestingly, Mosca predicted the essence of what many sociologists of education in the conflict tradition would be writing about fifty years later. Even when access to power is theoretically open to people from other social classes, as is the case in a society that preaches "equality of opportunity" and offers free public education, there is great difficulty in overcoming the special advantages that individuals socialized within 
the ruling class acquire throughout their lives. Mosca does not see this difficulty as a result of the children of the elite inheriting their parent's intelligence, but rather of the long preparation, ${ }^{9}$ connections, and kinships (social capital), that set an individual in the right road (1939:61). The lower classes are kept out, not by law or hereditary privilege, but by "a silken thread of subtlest fiber - a difference in education, in manners, in social habits" (Mosca 1939:114). ${ }^{10}$

The functionalist approach in sociology of education has spawned a tradition of quantitative research that attempts to find whether social mobility is increasing in societies that have undergone an educational expansion. Within this approach, status attainment theory affirms that western nations distribute status and material rewards in a meritocratic fashion. Schools play the role of sorting and selecting students according to ability and motivation, offering the most able an education that will entitle them to occupations of higher status and financial rewards. According to this line of thought, there is an expectation of individual attainment with only limited correlation between parents' occupational status and students' status. Overall, research has not supported these optimistic expectations (Saha 1987).

Large-scale surveys looking for an explanation for differential achievement have relied on concepts such as "ability," mostly defined as I.Q. " as well as aspirations and peer pressure. Findings have been consistent, pointing to the importance of student characteristics in school success, as opposed to school characteristics. ${ }^{12}$ The functionalist model has been criticized for measuring ability at an age when students have already been exposed to extensive (and differential) schooling (Hurn 1993:164-6), as well as for not working well with black students. Black students' ability test scores do not predict 
their achievement as well as it does for whites (Gottfredson 1981). The model also does not look at what happens inside the schools, keeping it a "black box" which bears no responsibility in the making or the maintenance of social inequality (Barr and Dreeben 1983; Karabel and Halsey 1977).

The conflict paradigm asks related questions, but due to its assumptions about the role of schooling in the reproduction of social inequality, it emphasizes different aspects of the problem. The focus here goes beyond the issue of correlation between certain variables to understanding the mechanisms by which the curriculum and the organization of schooling interact with the cognitive and behavioral styles of students from different socio-economic and cultural backgrounds, leading to either success or failure. As a result, the tradition has produced an entirely different line of inquiry, both from the Marxist and from the non-Marxist point of view.

The Marxist point of view is best known through the work of Bowles and Gintis. Their central idea is the correspondence principle: the social organization of the classroom mirrors the social organization of work. "Schools do different things to different people" (Bowles and Gintis 1976). This happens not only through the explicit curriculum (what is taught in the classrooms), but mainly through the hidden curriculum (the attitudes and personality traits taught in school, as well as general knowledge about life and one's place in society). The correspondence principle asserts that schools prepare students from different backgrounds to assume different occupational roles in society: while elementary schools emphasize rule-following by limiting and channeling the activities of students, high school education allows for more independent activity and less overall supervision. At the higher education level a more open atmosphere 
emphasizes the internalization of societal norms (such as punctuality, neatness, organization) while giving students much more freedom. Within each of these levels of education, different programs also offer different types of training. Evidence to this comes from the fact that gifted programs in general offer more opportunities for independent and creative work while children placed in regular classes and particularly in the lower ability groups are expected to learn through rote repetition, and a strong emphasis on discipline (McDermott 1977; Rist 1970).

Bowles and Gintis' work has been criticized (as many other Marxist works) for its economic determinism (Cole 1988). The assertion that children of parents with upper socio-economic standing often achieve upper socio-economic status, while children of lower socio-economic parents acquire a correspondingly lower socio-economic status cannot explain why some children cross over from the status of their parents. The correspondence principle does not provide an answer the question of how schools help transmit the status and class positions of the wider society. "Social reproduction, as it turns out, is more than simply a case of economic and class position; it also involves social, cultural and linguistic factors" (McLaren 1998:190).

Another classic work in the social reproduction paradigm is that of Pierre Bourdieu (Bourdieu and Passeron 1977), whose central focus is not economic but what he labels cultural capital. Bourdieu as well as others in the same line (Apple and Weis 1986), emphasizes the explicit curriculum in the effects of schooling. Schools, in Bourdieu's view, teach the superiority of a particular form of culture, in this case classical, European "high" culture. In France, the emphasis is on the study of Latin and Greek, and on a specific way of using language. Students reared in homes and broader 
social environments that expose them to "high culture" (classical literature, classical music, classical dance, and museums) speak and write in the fashion endorsed by the schools. Thus, children of the upper classes profit from their "cultural capital" in general and even more from their "linguistic capital," or an ability to communicate in the very specific form used in schools. In his research in France, Bourdieu found that most students who lacked this kind of knowledge were not promoted to the higher tracks or the elite schools, and were, thus, eliminated from the competition for the most prestigious occupations. Those few students from the lower classes who made it into the most prestigious tracks performed better in terms of their grades and achievement than their upper class peers. This is due to a process of "unequal selectedness." If only a very small group of lower class people are allowed, or "selected" into higher tracks, they are usually more qualified than those from the dominant group (Bourdieu and Passeron 1977:72).

I will argue that American schools differ from French schools in their degree of enforcement of elite high culture. American public schools are more open, at least in theory, ${ }^{13}$ and pay lip service to the idea of multicultural education ${ }^{14}$ (Freedman Lustig 1997). In addition, I suggest that knowing how the educational system functions, and understanding the implications of the tracking system are just as important as linguistic capital, in terms of the kind of "cultural capital" required by American schools. Recent immigrants find themselves at a disadvantage in terms of both of these kinds of capital. 


\section{Theory and Research on Immigrant Minorities and Education}

"The history of the use of IQ tests in the United States and the interpretations of the results of these tests by psychologists is not something of which the scientific community can be proud." (Hurn 1993:144)

The development of measures of ability is inextricably linked to efforts by parts of the "scientific community" to demonstrate the intellectual inferiority of particular immigrant or minority groups (Hurn 1993; Kohl 1994; Portes and Schauffler 1996). Writing about the relationship between language and educational achievement in the U.S., Portes and Rumbaut (1996:197) point to the fact that in the beginning of the twentieth century the relationship between lack of English and lower intelligence was treated as a "settled matter." Scientists ${ }^{15}$ simply attempted to determine a matter of causality: some stressed the environment, affirming that the immigrants' lack of English caused their lack of intelligence, while others stressed nature, or genetics, asserting that low ability accounted for immigrants' inability to learn English ${ }^{16}$ (Portes and Schauffler 1996:11).

Underlying the "nature" side of the debate was a strong belief in the importance of heredity; certain groups simply did not have the necessary ability to learn English and to function in the American "complex culture" (Portes and Rumbaut 1996:198). ${ }^{17}$ This research tradition did not see a need to control for social class; it compared the achievement of poor recent immigrants of peasant origin with those of middle class white Americans. Not until the 1960's were these views challenged by research that controlled for social class and demonstrated that true bilingualism (being able to 
communicate competently in two languages) was actually associated with higher scores on intelligence tests (Portes and Schauffler 1996:11). ${ }^{18}$

Later, educational psychologists stressed the environment as the main cause for the low achievement of immigrants, arriving at opposite conclusions from their predecessors. The cause of immigrants' low achievement was nurture, or the home environment, and not nature, or genetically determined ability (Portes and Rumbaut 1996:196-199). These views also remained strong in the scientific community until around the 1960's when researchers with a different set of assumptions contested their work. Until then, most researchers mentioned above ignored accusations that bias had been intentionally introduced in the ability measurements. ${ }^{19}$ At least in the case of the early I.Q. tests used by the Army, ${ }^{20}$ these accusations had been raised as early as 1925 . Ability tests frequently contained many items that could not be familiar to individuals from different cultural backgrounds. However, results of these tests were used to make assertions about the innate intellectual potential of recently arrived immigrants who joined the Army as well as of Native Americans and African Americans (Block and Dworkin 1976; Hurn 1993:144). Whether in its nature or nurture formats, the view that low achievement in standardized tests is due to reasons outside the control of the school has continued to permeate explanations of minorities' low achievement. Beginning in the 60's the effect of bilingualism and immigrant experience on school performance has been reassessed (Portes and Rumbaut 1996:199). Empirical research on immigrants' IQ and achievement that controlled for social class and other demographic variables contradicted four decades of prior research (Portes and Rumbaut 1996:200). Early studies on the relationship between bilingualism and intellectual ability 
had serious methodological flaws. Not only did they lack control for socio-economic or other demographic variables, but they also failed to assess the immigrants' actual degree of bilingualism. Researchers attributed low scores in tests to lack of ability when they were in fact due to lack of understanding of the English language.

Through the years it became clear that not all minorities and immigrant groups followed the same pattern of low achievement. The question thus shifted, from whether the problem was a result of immigrants' abilities versus home environment, to issues of how specific linguistic and cultural characteristics related to the schooling experience, leading towards either success or failure. ${ }^{21}$ Starting with George and Louise Spindler (1955), anthropologists became interested in the effects on academic achievement of cultural discontinuities between home and school. In the 1950's the Spindlers began ethnographic research in schools. Since then, a debate between two main research paradigms, one macro- and one micro-ethnographic, has shaped the discussion regarding immigrant and minority educational achievement (Trueba, Cheng, and Ima 1992).

Within the macro-ethnographic paradigm, John Ogbu (1987) developed the "cultural-ecological" model, a reaction against theories of cultural deprivation and genetic and biological determinism. In Ogbu's framework, "the initial terms of a minority group's incorporation into any society affects that groups' understanding of their social reality or their cultural model. That understanding, in turn, affects both their general adaptation to minority status and their adaptation to schooling" (Ogbu 1990).

The cultural ecological model classifies minorities into three different types (Ogbu 1987). Involuntary minorities are groups incorporated either through slavery, such as African-Americans, or by conquest or colonization, such as Native Americans 
and Mexicans. In Ogbu's earlier works these were called castelike or subordinate minorities. Groups who came to America more or less voluntarily in search of better opportunities or greater political freedom are called immigrant minorities. A third category in Ogbu's framework is that of autonomous minorities, such as Jews and Mormons in the United States. These autonomous minority groups constitute minorities only in the numerical sense. Although they may be victims of prejudice, they are not victims of stratification. These minorities usually have a cultural frame of reference that encourages academic success. This cultural frame of reference may well be part of the reason for these groups' continued economic success, in addition to the fact that they tend to look like mainstream "whites." The cultural-ecological perspective does not dwell long enough on the issue of the relevance of a "frame of reference" (cultural capital) that correlates to high achievement in academic environments. The issue of cultural capital that different groups bring to school thus disappears from the picture.

Immigrant minorities perceive differences between their culture and the dominant culture (primary cultural differences, in Ogbu's terms) as necessary barriers to be overcome, part of their migratory experience. Involuntary minorities view differences between their culture, one that is a product of contact with the dominant culture, and the dominant one (secondary cultural differences) as a threat to their group identity (Ogbu 1990). As a result of these differences, each minority perceives and reacts to their school experiences differently. Involuntary minorities usually develop a "cultural inversion" model where academic success is perceived as betraying one's own culture and community. The involuntary minorities' negative experience in the post-school opportunity structure also influences how their youth perceives their own future 
economic opportunities (Gibson and Ogbu 1991). Negative academic orientation becomes the normative adaptive strategy for these minorities, who reject the dominant culture and see little value in schooling (Ogbu 1987).

Ogbu's theory in a certain sense matches Saha's (1987) point of view on the social reproduction versus social mobility role of schooling. Immigrant minorities, because of the way they perceive and adapt to the discontinuities between their home culture and the school culture, fit into a social mobility model while social reproduction is the norm for involuntary minorities, their resistance strategies acting against their best interests.

Ogbu's work has been criticized on several points. Empirical findings on minorities show variability within ethnic groups that cannot be accounted for within his framework. The cultural ecological model does not offer any explanations for the successful members of involuntary minorities or for the failure of so many immigrant students. In short, the model can be criticized for being too deterministic in its dichotomous nature (Gibson 1997). Another problem with the typology of minorities is that the categories in the model are neither clearly defined nor mutually exclusive. The distinction between autonomous and immigrant minorities is far from clear. Refugees, for example, do not necessarily fit any of the categories available (Trueba 1988). In a theme issue of Anthropology and Education Quarterly dedicated to reviewing Ogbu's typology, Margaret Gibson concludes that "empirical reality is far more complex than what can be explained through dichotomous typologies of accommodation and resistance, success and failure, or immigrant or involuntary minorities." (Gibson 1997:441) 
In the aggregate there is mounting evidence that immigrant minorities are more successful in school than nonimmigrant or involuntary minorities (Gibson 1997:320321; Kao and Tienda 1995; Portes and Rumbaut 1996; Rumbaut 1995). On the other hand, findings of several researchers testing Ogbu's categories in different countries show many involuntary minority students do well while many immigrant students do poorly (Eisikovits 1997; Eldering 1997; van Zantan 1997). They also found that the same student, or different siblings in the same family, can present qualities associated with both involuntary and immigrant minorities (Gibson 1997).

Ogbu's theory assumes that school success necessitates cultural assimilation, or “crossing cultural boundaries," but empirical research has shown alternative models of resistance associated with success. Achor and Morales (1990), in a study of Chicanas holding doctoral degrees found a mode of resistance to institutional barriers characterized by challenge tempered by accommodation. These minority students challenged the involuntary minority pattern by contesting the barriers encountered while emphatically rejecting underlying messages of their unworthiness (Achor and Morales 1990). In broader terms, there is evidence supporting an additive view of culture, as opposed to the subtractive view that in order to learn to function in a new culture one must abandon their own culture (Gibson 1997:441; Suarez-Orozco 1989b:92).

Another major criticism to Ogbu's model is that there is very little place in it for human agency or for school effects since the path toward social mobility or social reproduction is pre-determined by the type of minority one belongs to (Gibson 1997; Trueba 1988). There is little schools can do to change one's academic orientation since it 
is a result of "societal forces" interacting with "culturally determined boundaries" (Trueba 1988).

Portes (1995) suggests another model to explain immigrant school performance, relating it to the direction of assimilation. He coined the term segmented assimilation to account for the fact that immigrant groups do not always follow the expected model of assimilation into the American mainstream and upward mobility. This segmentation is a consequence of the interaction between the social context in which children of immigrants grow up and different patterns of generational acculturation. Portes and Rumbaut (1996:248) identify three contextual factors constraining the chances for successful adaptation for children of immigrants: skin color, geographic location and changes in the structure of labor markets. As far as the labor market is concerned, our post-industrial economy results in very different opportunities for unskilled workers compared to the turn-of-the-century. A high school degree no longer guarantees a decent paying job. On the issue of skin color, at the turn of the century immigrants such as Italians, Greeks and Polish have been considered a different race, but over the years, they have become incorporated into "the white race." More recent immigrants, however, do not seem to have this opportunity since half of the children of immigrants residing in the United States today consider themselves to be non-white (Rumbaut 1996:121). The third factor influencing the direction of assimilation is geographic location. Poor immigrants who settle in urban ghettos find themselves surrounded by crime, poverty, and high unemployment rates.

Portes and Rumbaut (1996) also identify different possibilities in terms of generational acculturation patterns. When parents and children follow the same direction 
of acculturation, regardless of whether it is towards acculturation or not, there is generational consonance. The opposite, a situation where children might acculturate and parents not, or they do it at different rates, is called generational dissonance. A third option, typical of ethnic enclaves, is that of selective acculturation, also called accommodation without acculturation (Gibson and Ogbu 1991), one where immigrants learn to succeed in the host country while keeping their culture of origin. The interaction between the specific social context they join and the pattern of generational acculturation they follow leads immigrant groups either to the traditional pattern of upward assimilation into the middle class, or to downward assimilation, into poverty and the under-class. A third possibility is a pattern of assimilation associated with selective acculturation, where a group preserves its culture, but assimilates economically into the middle class. Portes and Rumbaut's model is one that in some way balances between human agency (the choices made by immigrants regarding whether or not to acculturate and at what speed) and structural constraints such as the economic and social contexts into which immigrants are inserted. This model seems more balanced between macro and micro approaches, allowing space for the social capital of immigrants, as well as the individual characteristics of students. Still, the theory does not deal in detail with school effects.

In contrast, context-specific approaches "view school experiences as determined by interaction patterns and the immediate social psychological characteristics of the learning environment" (Trueba 1987a:5). Context-specific approaches focus on the organization of teaching and learning activities, and as a consequence its methodology is mostly based on micro-ethnography. According to Trueba (1988:280), this tradition was 
established by educational anthropologists, led by George and Louise Spindler. They emphasize the "rich and multiple strategies for adaptation taken by individuals sharing the same culture and the same social pressures from mainstream cultural institutions" (Trueba, Cheng and Ima 1992:3). Macro-ethnographers, such as Ogbu, consider the micro-ethnographic tradition myopic in its focus on communicative and cognitive styles and criticize the tradition for their intervention studies (Ogbu 1987:313).

The fact that some immigrant minorities with enormous cultural and linguistic differences succeed in school, along with the remarkable differences in success among individuals from the same minority group, point to the limitations of existing explanations for minority achievement. Neither the history of a group's incorporation into the mainstream culture nor the extent of cultural and linguistic differences alone can account for the success or failure of students in the school system. Both macro level, i.e., attention to social, political, and economic forces, as well as micro level, i.e., interaction between actors in specific social contexts need to be accounted for. Educational anthropologists need to shift back and forth between these two approaches (Trueba 1987b:2).

The work of Suarez-Orozco (1989b) is an example of this type of approach. Suarez-Orozco explained the positive academic orientation of recent immigrants and refugees from Central America in a psychosocially oriented investigation of two innercity high schools in the San Francisco Bay Area. According to this study, successful students chose an "additive" adaptive strategy, where they learned the language of the host society and acquired its requisite behaviors without giving up the essence of their shared cultural code (Suarez-Orozco 1989b:92). Another finding concerned parents' 
expectations, defined in the context of a dual frame of reference, where parents and students compared present opportunities in the United States with past realities of fear and economic scarcity (Suarez-Orozco 1989a:99). Most relevant to this discussion is the fact that in addition to students' characteristics, Suarez-Orozco's explanation of student performance also included the school context. Suarez-Orozco's work reports on how the learning environment in the poor, overcrowded, inner-city schools affects immigrant students (1987:290). It also includes the issue of gatekeeping, as was the case when counselors enrolled students in lower level classes which students had already successfully completed in their country of origin (Suarez-Orozco 1989b:102-103). This gatekeeping was done sometimes with the best intentions while at other occasions it was due to lack of room in the regular classes (Suarez-Orozco 1989a:103).

In summary, anthropologists have tried to answer to the question of why certain groups fail more often than others in two ways. The first consists of looking at the broad historical, social, political and economic relations between different minority groups and the dominant group. The second consists of examining more carefully the linguistic and cultural discontinuities between minorities and the schools they attend.

\section{The Theoretical Debate on Tracking}

While anthropologists remain caught in discussions of whether macro or micro ethnographic research better explains immigrant success or failure, sociologists have reacted to criticisms that they did not look at what happened in schools. As a result, they have produced an impressive amount of work documenting the ways in which schools privilege some groups of children and marginalize others (Oakes 1983; Seller and Weiss 
1997). One of the principal ways in which schools distribute differential opportunities is by grouping students on the basis of their alleged abilities, performances, or aspirations. In elementary schools, this is done mostly through ability grouping, where students are assigned to different groups inside the same classroom, working at different levels and paces (Pallas et al. 1994; Rist 1970; Rosenthal and Jacobsen 1968). Another way schools distribute differential access to more prestigious types of knowledge is by offering programs such as "gifted" programs, which emphasize more critical thinking and independent learning (Sapon-Shevin 1993). At the secondary level this is done through curriculum tracking, where students are assigned to different classes that lead into different sequences and different opportunities to learn (Oakes 1994; Stevenson, Schiller and Schneider 1994)

In theory, tracking refers to the practice of assigning students to instructional groups on the basis of ability. In the past, secondary school students were assigned to academic, general or vocational tracks that led to different programs that either allowed access to higher education or limited one to going on to the job market. Courses within those tracks prepared students either for college or for work. More recently, track categories have been eliminated and most districts now offer "comprehensive high schools," which claim to offer the same educational opportunity to everyone. However, in most of these schools students continue to be assigned to different course levels, such as advanced, honors, regular, or basic courses and also follow different course sequences. ${ }^{22}$ Higher level and in some cases, regular courses, are loosely equivalent to academic tracks, while basic and lower (remedial) courses are equivalent to the general tracks $^{23}$ (Hallinan 1994:79). Although there are some vocational tracks available in 
particular schools, acceptance into these more prestigious vocational tracks that offer good job perspectives also requires high level of academic performance. Within the context of "comprehensive" schools, ability grouping and tracking refer to a theoretically homogeneous grouping, one that places supposedly similarly able students in classes geared to their supposed ability level (Hallinan 1994).

Sociologists who see schools as agents of social mobility consider tracking as a neutral organizational practice whose aim is to facilitate instruction and increase learning. Tracking, according to its proponents, permits teachers to tailor instruction to the ability level of their students (Hallinan 1994:79). The assumption underlying the theory of tracking is that there are big fixed differences in ability levels of students and that they can best be instructed at that specific level. Different instructional treatments are therefore not only necessary because of their efficiency, but also morally justified as fair and democratic. A less often mentioned assumption is that bright students are held back by sitting in classrooms with less able peers. Within the social mobility perspective, placement in different tracks is determined mostly by academic criteria, but also includes motivation, generating homogeneous classes with respect to ability and effort (Hallinan 1994). The underlying assumption is that schools are actually able to objectively classify students according to their learning potential.

Within the social reproduction tradition, tracking is seen as one of the mechanisms through which schools selectively distribute access to more highly valued types of knowledge (Bourdieu and Passeron 1977; Oakes 1986). Schools are therefore not providing equality of educational opportunity, but instead are sorting and selecting students to receive differential educational opportunities. In the more radical view of 
Bowles and Gintis (1976), tracking does more than simply distribute differential academic opportunities. It fosters a completely different set of personality traits, according to one's future place in society:

For social reproductionists, vocational and general tracks emphasize rulefollowing and close supervision, while the college track tends toward a more open atmosphere, emphasizing the internalization of norms concerning work behavior. These differences in social relationships among and within schools, in part, reflect both the social backgrounds of the student body and their likely future economic positions. Thus blacks and other minorities are concentrated in schools whose repressive, arbitrary, generally chaotic internal order, coercive authority structures, and minimal possibilities for advancement ${ }^{24}$ mirror the characteristics of inferior job situations. Similarly, predominantly working class schools tend to emphasize behavioral control and rulefollowing, while schools in well-to-do suburbs employ relatively open systems that favor greater student participation, less direct supervision, more student electives, and, in general, a value system stressing internalized standards of control. These differences do not occur by accident; rather, they reflect the educational objectives and expectations of teachers, parents, and administration (Cole 1988:3).

Opponents of tracking affirm that it has a negative effect on the self-esteem of students categorized as being of "low ability" (Kelly 1975). Tracking is said to influence students' future educational plans both by affecting the students' self perception as well as teachers' expectations (Alexander, Cook, and McDill 1978). The argument for detracking affirms that not only is tracking deleterious for most students, ${ }^{25}$ but also that heterogeneous grouping and the cognitive diversity that it creates is an effective teaching 
technique on its own (Oakes 1994). Oakes, a strong opponent of tracking, argues that it cannot be treated as a disembodied practice. Rather, the inequalities that tracking reinforces are an inherent part of the practice of curriculum tracking itself (Oakes 1994:85). The structure of tracking is embedded in cultural and political contexts. Historically, tracking has been associated with providing education that will fit students "equally well for their particular life work" (Lazerson 1974; Oakes 1994). Tracking is related to social inequality in terms of preparing differently abled students to different careers, and as such, it has never been a "neutral" method of the organization of instruction.

These different views of tracking in relation to equality of opportunity have generated a heated debate. Riordan (1997:184) compares the debate on tracking and detracking to the one regarding policies of integrated and segregated schooling. Furthermore, the idea of detracked schools raises a fear of "bright flight," much in the way that desegregation created "white flight" towards suburbia. Since curriculum tracking results in within-school segregation, with minorities making up the majority of lower track classes, and majority students concentrated in the upper track classes, there is an expectation that detracking might lead a large number of high achieving white students to transfer to private schools (Hallinan 1994).

\section{Empirical Research on Tracking}

\section{Tracking and Student Achievement}

Although in theory the educational experiences of students in different tracks should lead to an improved achievement for all groups, research on the effects of 
tracking does not support this claim. Empirical research on the effects of tracking on learning reports positive effects with high achievers only (Alexander, Cook and McDill 1978; Hallinan 1994; Oakes 1983; Rosenbaum 1976). Controlling for ability, students in higher tracks show greater gains through time and their scores become increasingly differentiated (Alexander, Cook and McDill 1978). Ability grouping and tracking were shown to affect students' learning through quantity, quality and pace of instruction (Gamoran 1987; Gamoran and Berends 1987; Pallas et al. 1994:27). Students in lower ability groups are taught less material, their curriculum is less challenging, and the pace of instruction is slower, so that the gap between the lower ability groups and the higher ones is constantly increasing. Lower track classes not only provide fewer learning opportunities, but teachers in these classes expect less of students (Oakes 1985; Rist 1970). Students in these classes are exposed to a curriculum that is more restricted in scope and in exposure to resources and opportunities (Gamoran 1987; Gamoran and Berends 1987; Oakes 1995; Stevenson, Schiller and Schneider 1994). Because both contents and methods of instruction vary between tracked classes, students in the high tracks have access to knowledge that is more highly valued in society, thus increasing their cultural capital and opportunities for social mobility (Bourdieu and Passeron 1977; Gamoran 1987; Oakes 1983:803).

Summarizing knowledge on the effects of grouping and tracking in secondary schools, Gamoran and Berends (1987) find that, despite inconsistencies in survey analyses, the balance of ethnographic evidence suggests that they do affect achievement. A survey analysis of a nationally representative sample from the High School and Beyond Dataset led Gamoran (1987) to conclude that the difference in achievement 
between tracks exceeds the gap between students in school and dropouts. He suggests that students' choice of courses in school may be even more important for the development of cognitive skills than whether one is in school or not (Gamoran 1987).

\section{Tracking and Segregation}

Research shows that tracking practices result in within-school segregation (Hallinan 1994). There is a consistent positive relation between both race and socioeconomic status and track level, with minority and lower socio-economic status (S.E.S.) children found disproportionately in classes at the lowest track levels (Hallinan 1994; Kalmijn and Kraaykamp 1996; Oakes 1983). Conversely, even after controlling for ability, children from upper S.E.S. are over-represented in higher tracks (Oakes 1983; Rosenbaum 1976). Tracking practices therefore place originally socially disadvantaged students at further educational disadvantage (Oakes 1994).

\section{Tracking, Placement Practices, Ability and Cultural Capital}

Placement practices are a problematic area for supporters of tracking. Hallinan (1994), while defending the practice of tracking, admits that actual placement practices produce groups that are far from homogeneous, and suggests a stricter enforcement of "objective" measures of ability and achievement (Hallinan 1994). The evidence indicates that the classification process is rarely well defined or consistently carried out. Indeed, there may be no valid objective measures. Standardized tests of achievement or aptitude are problematic because they are inappropriate for students with language or 
cultural differences and their use results in many minority students being inappropriately placed in lower tracks (Oakes 1983; Zehler et al. 1994).

Both sides on the debate recognize that, in practice, placement of students reflects more than strictly academic considerations such as grades, standardized tests scores and the recommendations of teachers and counselors. Defenders of tracking mention course conflicts, co-curricular and extra-curricular schedules, students' work demands and teacher and curricular resources as non-academic factors influencing placement (Hallinan 1994:80). Hallinan admits that after controlling for achievement the race-ethnicity and income effect on track placement decreases, but does not disappear (1994:80), a clear indication that race, ethnicity and income discrimination influence track placement (Oakes 1994:88). Stevenson, Schiller, and Schneider (1994), for example, found that the level and topics of math that students take in eighth grade are closely related to what they take in high school, regardless of their academic performance.

In most cases placement criteria are not publicized ${ }^{26}$ and many parents and students are not well informed regarding either placement criteria or the consequences of placement in each class. Again, the practice discriminates against low S.E.S. and minority parents who are not as likely to exert pressure on the school regarding their children's placement (Oakes 1994:88). Foreign parents are frequently not aware of the implications of track placement in terms of their children's future opportunities and do not know that they can override school placement decisions. A study on parental involvement in children's education found that it tends to be less in schools with higher concentration of minority students (Carey, Lewis, and Farris 1998). Another study 
focusing on LEP students only reports that, according to teachers interviewed, parents of LEP students are substantially less involved in school functions, or as classrooms or school volunteers, than parents of non-LEP students (Fleischman and Hopstock 1993). The study also found that, similar to majority parents, LEP parental involvement is highest in elementary school and gradually decreases in secondary school. In addition, given the current debate over anti-immigrant legislation, it is reasonable to assume that parents who are not legally in the country are resistant to contact the school system, and all the more so to express disagreement with school practices.

The lack of uniformity and objectivity in track placements is clear in the finding that ability-group placements are not reliable. Two related findings support this assertion. The first one is that children with comparable levels of academic performance can be found in tracks that rank anywhere from the top of the class to near the bottom (Hallinan 1994; Oakes 1995; Pallas et al. 1994). The second finding is that the distribution of achievement in tracks overlaps the distribution of the adjacent tracks (Hallinan 1994:81; Oakes 1994:87).

\section{Institutional Effects of Tracking, Detracking and Untracking}

Another line of inquiry on the effects of tracking looks at the hierarchy of teaching that develops in association with tracking. Finley (1984) found that, at the institutional level, tracking serves the schools' needs to reward personnel. Teachers compete for high achieving students in higher track class assignments (Finley 1984). Low track teaching assignments are less preferred by teachers and are usually left for the 
newcomers in the schools, who often are the least experienced teachers or are not certified to teach assigned subjects (Oakes 1983:803; Oakes 1990).

The dismantling of the tracking system in one school system in one comprehensive effort is called detracking (Oakes 1983) or heterogeneous grouping (Cooper 1996:192). In a qualitative study of a school undergoing reform that included detracking, Datnow (1997) found that detracking was perceived by teachers as changing the distribution of power and privileges of teachers as well as of students. In a quantitative study of a California high school, Cooper (1996:205) found that the institutional culture -- that is, the norms and ethos that drive the policy and practice within an institution such as the school -- can be either a barrier or a facilitator of change. The process requires effort on the part of the teachers to learn and implement new methods of teaching appropriate for heterogeneous classes. When the principal and administrative staff did not devote enough time and resources to helping teachers develop the techniques and strategies needed the process of detracking was undermined (Cooper 1996:205).

In addition to the institutional culture, detracking efforts also reach a point where they are opposed by some types of parents. In a national, three-year, multiple site qualitative case study of schools undergoing detracking, Wells and Oakes (1996:139) found that parents of high achieving or identified "gifted" students demanded greater differentiation between what their children learned and what was offered to other students. Detracking efforts are undermined by these issues if they are not taken into account when planning for changes (Datnow 1997). 
Mehan et al. (1994) report on an alternative solution to the problems of tracking that avoids some of the pitfalls of detracking. Untracking is the process of assisting a small number of students to move from general and vocational tracks to the college preparatory track. The process included providing increased support by explicitly teaching low-income students the implicit culture of the classroom and the hidden curriculum of the school. Mehan et al. (1994) suggest the use of untracking as an initial step in a detracking effort.

\section{Research on Assessment of Limited English Proficient Students}

Fleischman and Hopstock (1993) using 1991-92 national data, found a 70 percent increase in the number of LEP students since their 1984 descriptive study. The study found that, despite the lack of standardization in methods for identifying LEP students, most districts determine English language proficiency through the use of oral proficiency tests and a home language survey. ${ }^{27}$ Other measures often used to complement these measures are teacher judgment, achievement tests in English, and writing samples in English. Only 12 percent of the districts in Fleischman and Hopstock's sample tested for achievement in the child's mother tongue. The same researchers also found that 27 percent of LEP students in the average high school were assigned to grade levels that were at least two years lower than their age/grade norm, compared to 11 percent of all students. Figures for middle schools were 19 percent and 9 percent respectively. The researchers concluded that foreign students are coming in educationally disadvantaged. 
A 1994 study by some of the same authors (Zehler et al. 1994) notes that assessment and classification as LEP provides important access to special services, such as ESOL classes. However, they also point to the fact that this "May also limit the student in terms of future opportunities and unfairly exclude LEP students from other opportunities, such as for advanced or other special instruction" (Zehler et al. 1994).

Analysts of test outcomes often fail to recognize that outcomes of tests in English reflect the operation of both language proficiency and academic knowledge. The lack of English proficiency leads to LEP students' achievement being underestimated.

Research on the use of assessment has shown that LEP students are often assessed and inappropriately placed within special education, where they are more likely to receive low level instruction and less challenging content. Similarly, the use of single assessment measures that are inappropriate to LEP students may be the only means of qualifying for gifted and talented instruction or other instructional opportunities (ibid.).

Other problems found in the use of standardized testings with LEP students concern the cultural differences between language minority students and mainstream students. These cultural differences can also be responsible for a lower level of performance of language minority students in standardized tests. Zehler and associates raise the question of the different purposes of assessment and the need to keep these purposes in mind when implementing and using results. The report presents two broad separate categories: individual assessment aimed at identifying and assigning students to appropriate services, and group assessments aimed at evaluating the programs and at accountability of specific schools or districts. The authors recommend that results of standardized testing in English for LEP students be used only for group evaluations, and not for individual placement decisions. 
A major issue found by the Zehler group was the inappropriate use of assessment results to place LEP students in programs that limit their educational and career opportunities. Recommendations include the use of other means of assessment that can better measure LEP students' content knowledge; including assessment in native language. Multiple measures are recommended for placement purposes. The authors also recommend avoiding standardized testing of LEP students until they have received formal language instruction in English for a minimum of one and one-half years. They also recommend that the presentation of results state clearly that academic achievement levels of LEP in English may not be related to their achievement levels in the native language (Zehler et al. 1994). 


\section{Chapter III Setting}

\section{The School District}

This project was carried out in Dade County, Florida. Miami-Dade County Public Schools (M-DCPS) is the fourth largest public school system in the country. Miami has the highest percentage of foreign-born residents of any major U.S. city, estimated at 45 percent (Stepick 1995). According to the district's estimates, more than half of its students speak a language other than English at home. More than 25 percent of the student body is foreign born.

For the 1996-97 school year, out of its 340,904 students, ${ }^{28} 48,749$ were classified as LEP. Over a hundred different national origins are represented in M-DCPS (MiamiDade County Public Schools 1998b). Overall, 15 percent of the district's students were classified as LEP, while 10.2 percent of high school students were LEP. The number of students enrolled in English for speakers of other languages (ESOL) in secondary schools (from $6^{\text {th }}$ to $12^{\text {th }}$ grades) went from 9,155 in $1900-91$ to 14,298 in $1996-97$ (Miami-Dade County Public Schools 1997d). Within the LEP population in M-DCPS, an estimated 84 percent are of Spanish language origin and 14 percent are of HaitianCreole origin. The remaining two percent represent diverse language backgrounds (Miami-Dade County Public Schools 1995b:23).

Dade County has both Hispanic (Black and non-Black) and Black (nonHispanic) immigrants, from poor, middle class and even elite backgrounds. Immigrants and native-born minorities can be found in inner city, suburban and rural neighborhoods (Stepick 1995). Hispanic immigrants come mostly from countries such as Cuba, Nicaragua, Mexico, and more recently, the Dominican Republic. ${ }^{29}$ Black immigrants to 
Miami come mainly from Haiti and the Caribbean, and a few from Africa. Principals, counselors, and teachers attested that these immigrants are no exception to their predecessors in their aspirations for social mobility. The students also believe that a college education is the key to this mobility. ${ }^{30}$

As in some other large U.S. school districts, such as New York and Los Angeles, white non-Hispanic students account for less than half of the student body. More than half of the student population in the district is classified as Hispanic, a label that includes anyone descended from native Spanish-speakers. Thirty-four percent of the districts' students are classified as Black, without regard to issues of national origin. Therefore, most district statistics regarding Black students include African-American and Haitianborn students, as well as English-speaking West Indians in the same category.

This study was carried out in two schools: King High and Northern High. ${ }^{31}$ King High is located in one of the most racially segregated neighborhoods with the largest African-American concentration in Dade County. Nearly 85 percent of the population is Black, and about 13 percent are Hispanic, mostly recent arrivals from Central-America and the Dominican Republic. The school is located in an inner city area that is home to some of the poorest of Miami's residents. Adjacent to this neighborhood, and still part of the King's boundary zone, is another area with a large concentration of Haitians, including many recent arrivals.

Northern High is located in an older suburban neighborhood not far from King High. An overwhelmingly white area through the 1970's, beginning in the early 1980 's it has become increasingly minority populated. African-American and Caribbean Blacks, as well as Hispanics have settled in the area. The neighborhood's population is 
predominantly middle-class, and the area is a desired destination for many of those living in King High's boundaries who can afford to move up to a "better" area (Stepick $1995)$.

Table 1: $\quad$ School Information 1996-97 ${ }^{32}$

$\begin{array}{llll}\text { Location } & \text { All High Schools } & \text { Northern H.S. } & \text { King H.S. } \\ \text { Total \# of Students } & 82,757 & 2,481 & 2,430 \\ \text { School Capacity } & \text { N/A } & 2,211 & 2,064 \\ \text { Percent Utilization } & \text { N/A } & 110 & 116 \\ \text { \# ESOL Students } & 7,903 & 466 & 607 \\ \text { Percent LEP } & 10.2 & 18.9 & 25.0\end{array}$

At the beginning of the project's research data collection both schools were in the list of critically low performing schools. Both were removed from the list due to their performance in the Florida Writes test. In general, their results in standardized tests are below district's averages, which in turn are below the State's averages. Table 2 shows State, District and school median percentiles in the Stanford Achievement Test (1996) and the Grade Ten Assessment Test (GTAT, 1996-97), and mean scores in the College Board SAT I (1996). Each of these tests has a language and a math component. 
Table 2- Indicators of School Performance ${ }^{33}$

\begin{tabular}{lllllll} 
Location & $\begin{array}{l}\text { Stanford } \\
\text { Verbal }\end{array}$ & $\begin{array}{l}\text { Stanford } \\
\text { Math }\end{array}$ & $\begin{array}{l}\text { GTAT } \\
\text { Verbal }\end{array}$ & $\begin{array}{l}\text { GTAT } \\
\text { Math }\end{array}$ & $\begin{array}{l}\text { SAT I } \\
\text { Verbal* }\end{array}$ & $\begin{array}{l}\text { SAT I } \\
\text { Math* }\end{array}$ \\
Florida & N/A & N/A & 47 & 54 & 505 & 508 \\
M-DCPS & N/A & N/A & 31 & 38 & 461 & 465 \\
Northern & 39 & 39 & 22 & 26 & 440 & 456 \\
King & 11 & 15 & 13 & 13 & 344 & 380 \\
\multicolumn{7}{l}{$*$} \\
$\quad$ * 77 students tested at King and 226 at Northern. First line refers to National mean scores.
\end{tabular}

The county has developed Magnet Programs (and Schools) in an effort to balance racial ratios, stem declining enrollment and improve the quality of education (Miami-Dade County Public Schools 1997b). The School Board is very clear about the fact that Magnet Programs are to be used to further the district's desegregation goals. Magnet programs are supposed to recruit students with the goal of achieving a Black/Non-Black student population proportionate to the Black/Non-Black population districtwide. Exceptions may be granted in order to further desegregation of the receiving school's total population. However, no more than 80 percent of the students can be of any single race in a Magnet Program. The School Board Rule also requires enhancement opportunities be provided to prepare students including at-risk, handicapped and LEP for magnet program entry (Miami-Dade County Public Schools 1997b).

Northern offers an International Baccalaureate (I.B.)/ International Affairs (I.A.) Magnet Program. This is a highly demanding academic program with academic performance pre-requisites. Students are recruited into the program at $9^{\text {th }}$ grade. Northern was primarily a 10-12 grade school in the first year of this study, when only 
pre-I.B. students did their $9^{\text {th }}$ grade at Northern. The following year (1997-98), $9^{\text {th }}$ graders from the regular feeder pattern began attending Northern. ${ }^{34}$

In addition to the I.B./I.A. program, Northern offers vocational training programs in Cosmetology and an Allied Health Assisting program. The school also offers shared time programs with two Vocational schools, one focusing on Aviation, and the other offering a variety of programs in technical careers. King High offers the Allied Health program and the shared program with Aviation. Both schools offer a Junior Reserve Officers' Training Corps Program (JROTC) focusing on teaching leadership skills. The program does not require any commitment to military service. King High has no magnet programs.

The district uses three, four, five or six racial/ethnic categories, depending on the purpose of document or the mandate it is responding to when collecting the data. ${ }^{35}$ Information concerning the race and ethnic composition of every school is shown with six different categories: white, Black, Hispanic, Asian, American Indian and Multiracial. Information regarding Magnet Program enrollment classifies students as Hispanic, Black, or White/ Other, although the School Board Rule mentioned above only refers to Black/Non-Black proportions. Information on participation in advanced level placement courses students classifies students as Black (non-Hispanic), White (non-Hispanic), Hispanic, Asian / Other. Information regarding student achievement on standardized tests, truancy, and drop out rates refer only to Black, White, or Hispanic, with a breakdown by gender (Miami-Dade County Public Schools 1998b). The district mixes "racial" and ethnic categories in one classification system; a "Hispanic" student can be of any "race" as long as they come from a Spanish speaking country, while a "Black" 
student can be Haitian and speak Creole or French, African-American, African, or English-speaking Caribbean. The inconsistencies in the classification categories and the lack of availability of information on national origin associated to class placement render these statistics practically meaningless. ${ }^{36}$ A careful examination of the course credit analysis of one subsample of the project's subjects, a group of 30 Haitian students, yielded three classified as Hispanic. Students or parents are allowed to mark whatever racial/ethnic category they feel appropriate, and no one has the authority to question that choice.

Both school populations have radically changed over the last fifteen years. At Northern, a population that 20 years ago was suburban white middle class youth with a large Jewish component, gradually became mostly African-American. In the past five years the proportion of students of Haitian descent has been constantly increasing. The academically selective I.B. program at Northern brings some non-Black students to the school, and these I.B. students make up the vast majority of the advanced placement and honors classes. King High has a similar history of moving from a predominantly white middle class school to mostly African-American, and then shifting to a majority of students of Haitian descent. In the past few years an increasing number of immigrant Haitian, West Indian and Hispanic students have entered both schools. Haitian students now make up an estimated 40 percent at Northern and above 80 percent at King. 
Table 3: 1996-97 Student Membership by Race and Ethnicity

\begin{tabular}{|c|c|c|c|c|c|c|c|c|}
\hline \multirow[t]{2}{*}{ Race/Ethnicity } & \multicolumn{2}{|c|}{$\begin{array}{l}\text { White } \\
\text { Non-Hispanic }\end{array}$} & \multicolumn{2}{|c|}{$\begin{array}{l}\text { Black } \\
\text { Non-Hispanic }\end{array}$} & \multicolumn{2}{|l|}{ Hispanic } & \multicolumn{2}{|c|}{$\begin{array}{l}\text { Asian/Indian } \\
\text { Multiracial }\end{array}$} \\
\hline & Number & $\%$ & Number & $\%$ & Number & $\%$ & Number & $\%$ \\
\hline $\begin{array}{l}\text { All High } \\
\text { Schools }\end{array}$ & 12061 & 15 & 26647 & 32 & 42759 & 52 & 344 & 2 \\
\hline Northern. & 190 & 9 & 1809 & 73 & 409 & 16 & 73 & 3 \\
\hline I.B. Northern* & 112 & 42 & 84 & 31 & 74 & 27 & $\begin{array}{l}\text { *counted } \\
\text { White }\end{array}$ & with \\
\hline King & 11 & +0 & 2232 & 92 & 184 & 3 & 3 & +0 \\
\hline District Total & 44946 & 13 & 115735 & 33.5 & 179484 & 51.9 & 5696 & \\
\hline
\end{tabular}

Source: (Miami-Dade County Public Schools 1997d)

\section{The School Staff}

Regarding the ethnic composition of the staff, King has two native Haitian guidance counselors, but Northern has only one counselor who speaks Haitian Creole as well as Spanish. At Northern, this was the only counselor who spoke any language other than English during the 1996-97 year. At the beginning of the 1997-98 year, with the addition of the ninth grade to the High School, two more counselors were added at Northern, one of them African-American, the other Hispanic.

In the 1996-97 school year, the first year of data collection, the faculty at Northern High was mostly white (64 percent), with 26 percent Black and 5 percent Hispanic. The breakdown for guidance counselors was 50 percent White, 25 percent Black, and 25 percent Hispanic. The school profile mentions eight counselors, counting the five guidance counselors, the Trust Counselor, who was Hispanic, the College Assistance Program (CAP) advisor and the Occupational Specialist (both White non- 
Hispanic). At King High the ethnic breakdown for classroom teachers was 44 percent White (non-Hispanic), 33 percent Black and 21 percent Hispanic, with 1 percent Asian/American Indian. The ethnic breakdown for counselors was 50 percent White, 33 percent Black and 17 percent Hispanic.

Guidance counselors, together with several other professionals such as the Occupational Specialist and the CAP Advisor, are part of the Comprehensive Student Services Program (Miami-Dade County Public Schools 1995a). The program is meant to address the educational, career, and personal/social needs of all students in the county. The program's ultimate goal is "for students to graduate with the competencies necessary to make self-directed, realistic and responsible decisions and to be successful contributors to society" (Miami-Dade County Public Schools 1995a).

Counselors in both schools had caseloads ranging between 600 and 700 students. Guidance counselors are supposed to help students with their subject selections, make sure they are appropriate and that there are no repeatability violations (if a student takes the same course twice, no credit is awarded for the second time). Responsibilities of counselors include discussing students' course choices in relation to their career aspirations, dealing with course changes during the year, mediating between children and teachers when problems occur. Counselors are also expected to contact parents when students have discipline or academic problems, meet with parents who have questions or concerns about their children. Many of those responsibilities require filling out forms and other types of paperwork. An important part of a high school counselor's job is to make sure that $12^{\text {th }}$ graders fulfill all the requirements for graduation. These include: 
a) Completing all the required credits in each specific category (students may have more than 24 credits and still not have the half credit in fine arts, or practical arts, for example),

b) Having a G.P.A. above the required minimum (which is gradually changing from 1.5 to 2.0$)^{37}$,

c) Completing the community service report. Requirements vary depending on the type of certification the student is applying for.

d) Passing the High School Competency Test (HSCT), a test offered five times between junior and senior years. There are two parts to the HSCT: math and English. 


\section{Chapter IV Methodology and Limitations}

\section{Procedures and Subjects}

A variety of research methodologies were used in order to address the question of how tracking practices interact with educational policies that demand equality of access to educational opportunity for language minority students. The methodology includes content analysis of formal policies, interviews with district and school personnel, and participant observation in the student services departments of the two high schools. Pertinent policies included those concerning the evaluation and placement of LEP students in English for speakers of other languages (ESOL) programs, and those regarding the evaluation and placement of limited English proficient students, particularly in math and science courses. Written policies and statements regarding the expressed objectives of State and County programs created for LEP students were examined. School curriculum bulletins and other relevant school publications were used as additional data sources.

This research is part of a project called "The Academic Orientation of Nativeborn and Immigrant Minority Adolescents" (Stepick 1995). This longitudinal project is studying six immigrant-ethnic minorities (African-Americans, Haitians, West Indians, Cubans, Nicaraguans and Mexicans) in four different Miami-Dade county high schools. ${ }^{38}$ This study is based on research in two of those four schools. Access to the schools was granted by the district to the researchers working in the project. Researchers were also granted parental permission to study the school records of students in their samples. 
To protect the identity of those involved, I have called people and also schools by fictitious names. The sample includes staff in both schools with the main focus on those who have the greatest involvement in students' placement in academic classes: teachers, guidance counselors, department heads, and the principal and assistant principal for curriculum. $^{39}$

A major part of this research project consisted of fieldwork conducted while working as a school volunteer. Data collection began in October 1996, with visits to the middle schools in the feeder patterns of the schools in the project. ${ }^{40}$ Between January 1997 and February 1998 I engaged in participant observation, first at Northern High and from September 1997 to May 1998 at King High. I continued visiting Northern High, although less intensively through the beginning of the 1997-98 school year.

At Northern High School I was able to become familiar with all counselors, the assistant principal for curriculum, the secretaries and the College Assistance Program (CAP) Advisor. Besides the informal conversations I held with school staff while volunteering, I formally interviewed each of them once. As a volunteer, I spent several days helping the guidance counselor who is also the test chairperson responsible for standardized tests such as the High School Competency Test (HSCT), the Stanford Achievement Test (SAT), the Florida Comprehensive Assessment Test (FCAT) and the Florida Writes! test. At Northern High I was denied access to observing counselors while they were working with students in their offices. However, while working in the test chairperson's office and the College Assistance Program advisor's office I was able to observe some interaction between those counselors and students. 
Other opportunities for observing counselor-student interaction occurred at Northern during the many days spent doing clerical work at the student services main office area. I volunteered to help during subject selection week when all students go to the cafeteria to hand in their subject selection sheets and was able to observe studentcounselor interactions there.

At King High I also formally interviewed guidance counselors, the Trust

counselor, ${ }^{41}$ the assistant principal, and the principal. I also interviewed the teachers who head the ESOL department, the Math and the English department, and the math teacher who is also test chairperson. At King I was allowed to spend time with individual counselors and observe them as they worked in their offices.

\section{Limitations}

The data presented here have been collected as part of a larger project still in progress. The findings point in a certain direction but it would be presumptuous to assume they provide definitive answers to the question of how tracking practices affect the implementation of policies demanding equality of access to educational opportunity for language minorities. In both of the schools I studied the majority of students are of Haitian descent. In order to extend the conclusions reached here to other groups, further research is needed with immigrants of other nationalities.

The study describes some of the obstacles to access to educational opportunities in these two schools. Although the paper states the goals of the Consent Decree and how the district attempts to comply with some of the decree's requirements, it is not intended to describe the requirements in every detail. Requirements are described only to the 
extent that they are related to the main goal of access to educational opportunity and to what was observed in the schools. The study focuses on the interpretation and implementation of those requirements by the schools. The official requirements can be found in documents such as the Consent Decree (LULAC et. al. v. Florida Board of Education and Florida Department of Education 1990), the District LEP Plan (MiamiDade County Public Schools 1995b), and the Procedures Manual for Bilingual/Foreign Language Education (Miami -Dade County Public Schools 1995). 


\section{Chapter V Results}

\section{Understandable Instruction, Equality of Access to Educational Opportunity,}

\section{and Tracking}

Federal law and M-DCPS policy both use the language of equality of opportunity and of academic excellence, usually in the same sentence. The mission of the federal Department of Education, for example, is to "ensure equal access to education and to promote educational excellence throughout the Nation" (Office of Bilingual Education and Minority Language Affairs 1997). In 1968, recognizing that a growing number of limited English proficient children were not receiving the same education as their English speaking peers, the U.S. Congress passed the Bilingual Education Act. The purpose of the act was further explained in a 1970 memorandum sent by what was then the Department of Health, Education and Welfare ${ }^{42}$ :

Where inability to speak and understand the English Language excludes national origin minority group children from effective participation in the educational program offered by a school district, the district must take affirmative steps to rectify the language deficiency in order to open the instructional program to these students (Pottinger 1970:11595)

According to the goals of the Office of Bilingual Education and Minority Affairs (OBEMLA) publicized on the Internet, bilingual education is"a means to make it possible for linguistically diverse children to achieve the same challenging academic standards required of all children enrolled in America's schools" (ibid).

The same document also states that the role of bilingual education is grounded on two knowledge-based principles, and supported by research, although it is not cited. The first principle is that "all children are capable of engaging in complex 
thinking tasks, provided they receive high quality instruction and follow a challenging curriculum." This assertion is particularly relevant because it contradicts the principles and assumptions on which tracking and ability grouping are based. The second principle concerns the idea that "developing and maintaining the native language in no way interferes with English language acquisition." (Office of Bilingual Education and Minority Language Affairs 1997). Both assertions are a far cry from what cognitive "scientists" affirmed in the beginning of the century.

The Civil Rights Act of 1964 prohibits federally funded discrimination, which is understood to include unequal access to participation in school programs because of language (Castro Feinberg 1990). In 1974, the Lau versus Nichols decision established that the district must take affirmative steps to help students overcome their English language deficiency. ${ }^{43}$ However, education in the United States has traditionally been decentralized (Hurn 1993:22-24). States and districts have ample room to interpret these requirements, and research shows that implementation follows a variety of patterns (Fleischman and Hopstock 1993; Zehler et al. 1994). A large number of language minority students in the country in need of special services do not receive them (Castro Feinberg 1990). Many of the decisions concerning what happens in the schools are actually made in courts as a result of litigation (Castro Feinberg 1990; Hurn 1993:23).

The key to the problem seems to be the conflict between the rhetoric that all children can achieve if provided with appropriate, high quality instruction, and a continued practice of differential instruction, despite mounting evidence of the detrimental effects of ability grouping and tracking on the quality of instruction. 
Advocates for immigrant students in Florida brought suit against the State Board of Education and the State Department of Education aiming at compliance with federal requirements regarding children's rights to equal educational opportunities. In August of 1990 the United States District Court for the Southern District of Florida, in LULAC, et al. v. Florida Board of Education, et al ${ }^{44}$ sanctioned a settlement agreement that became known as the META agreement, or META consent decree. ${ }^{45}$ The agreement guarantees the rights of LEP students to "understandable instruction" and also aims to ensure that language minority students have equal access to all instructional programs and services. The decree provides a design and structure for compliance with federal rulings that protect the rights of language minority students (Office of Multicultural Student Language Education 1995). It requires any teacher who has LEP students in their classrooms to receive training to meet the instructional needs of these pupils, usually referred as META training (Miami-Dade County Public Schools 1998a). Schools are also required to provide understandable information to language minority parents and guardians.

Subsequent State interpretation of the Decree has led to the view that requiring LEP students to register at a centralized place would place an extra burden not required from other students. Therefore the State requires schools to provide assessment for these students in the school premises.

The Decree requires districts to provide access to all areas of the curriculum to LEP students. In particular, students must be provided with intensive English language instruction, and with understandable instruction in the other content areas, which may be provided through Home Language Methods, or through ESOL methods. Instruction must 
be equal and comparable in amount, scope, sequence, and quality to that provided to English proficient students, and appropriate to the students' English proficiency level, academic achievement, and special needs. The focus of content area instruction shall be substantive subject matter knowledge, parallel and comparable to that provided to nonLEP students in basic subject areas, consistent with state-required curriculum frameworks and performance standards. To ensure that districts are following these requirements, every district must have an LEP Plan.

M-DCPS LEP plan requires a school with fifteen or more LEP students of the same home language background to provide "instructional support in the home language" (Miami-Dade County Public Schools 1995b:23). The M-DCPS plan requires schools to provide "Basic Skills in the Home Language" ("Home Language Methods") and "Special Instruction in/through English" ("ESOL Methods").

In secondary schools, ${ }^{46}$ skills in language are offered in Bilingual Content Curriculum (BCC) classes that teach subject matters in a mixture of English and Spanish or Haitian-Creole as well as in Home Language Arts (HLA) classes which are offered in the students' language ${ }^{47}$. (Miami -Dade County Public Schools 1995:6). In elementary schools, enrollment in HLA is automatic, and parents can opt out of the program if they so desire. At the secondary level, language arts instruction in the student's home language that is in addition to the required ESOL courses is elective. For Haitian students who choose not to take Haitian-Creole the only language arts classes they receive is the ESOL. Although ESOL classes are supposed to have the same goals as those of English language arts classes, beginning students learning a new language deal with the complexities of learning a foreign language (English), not with the level of complexity 
required in a high school language arts course. As an ESOL department head explained to me, they can expose students to the story of a Shakespeare book, but they are nowhere near what is considered high school level work. In contemplation of this burden, the decree specifies that basic ESOL instruction may include special alternative language arts as necessary to attain parity of participation with non-LEP students in language arts.

An analysis of course taking patterns of Haitian students in the project's sample showed most of them took two years of French (I and II) and one or two years of Spanish. Although both schools offered Haitian-Creole, ${ }^{48}$ which is the language Haitian students speak at home, students in the sample at Northern chose French, which is considered a higher status language in Haiti. At King, some of the students in the sample chose Creole, offered only at level 1 . The teacher told another researcher in the project that students take it because it means some "down" time where they can chat in their home language, and get a good grade to raise their G.P.A. ${ }^{49}$. Neither those students taking French 1 or 2 , nor those taking Haitian-Creole 1 could be considered to be acquiring high school level language arts skills.

Special instruction in/through English is also provided in two forms. "English for Speakers of other Languages" (ESOL) is offered in four levels, and assignment to ESOL classes is automatic, based on the student's level. Students who test at level V are considered independent and mainstreamed into regular classes. The second form of instruction in/through English is called "Curriculum Content in English through ESOL" $(\mathrm{CCE} / \mathrm{ESOL})$ and refers to the use of ESOL strategies by subject area teachers in mainstream classes (Miami -Dade County Public Schools 1995:35). These teachers are required to complete the META training. In schools where the numbers of LEP students 
are as high as those in this study, this means that practically every teacher in the school will need to fulfill these requirements.

In both schools studied, secondary students classified as LEP were placed in ESOL classes as required by law. Students placed in ESOL I were required to take two periods of ESOL instruction per day, and this requirement was followed in both schools. These students took a regular ESOL class and a second period that could be dedicated to reading and writing, listening and speaking, or combined skills. From levels II to IV, the required time for instruction is one daily period.

Haitian students ${ }^{50}$ placed in ESOL I and II were given bilingual content curriculum (BCC) for the content areas of math, social studies, and science. These classes are to be taught in both the language of origin of the student and English. Bilingual textbooks should be available, but this was usually not the case for Haitian Creole BCC classes.

Students on ESOL levels III and IV were not placed in BCC classes and were mainstreamed to regular classes, according to level of performance in each subject. Teachers are thus expected to use the ESOL strategies taught at the META training to provide understandable instruction for their LEP students. Principals have access to the META screen that tracks the assignment of LEP students and are responsible for explaining requirements to teachers. Training requirements and the timeline for completion vary according to the teaching assignments (Miami-Dade County Public Schools 1997e; Miami-Dade County Public Schools 1998a:2). Content area teachers who teach math, science, social studies, and computer science must complete a 3 semesterhour course, or the inservice training equivalent of 60 contact-hours. Language arts 
teachers of LEP students, who need the Add-on ESOL endorsement, must complete 300 contact-hour inservice equivalent, or 15 semester-hour college courses. All other teachers are required to complete 18 contact-hours of inservice training.

In an effort to accelerate the level of inservice training the district was providing for teachers to comply with the Consent Decree requirements, in January of 1997 the district was offering ESOL telecourses in cooperation with WLRN (Miami-Dade County Public Schools 1997e). For content area teachers and grandfathered ${ }^{51}$ ESOL teachers, the equivalent to the 60 contact-hour training requirement consisted of 10 two-hour viewing sessions and 5 two-hour live sessions with trainers, totalling 30 hours. For teachers of other subject areas, the 18-hour training comprised 4 two-hour viewing sessions and 3 two-hour live ones, totalling only 14 hours. Teachers can also obtain META certification by completing the equivalent number of semester hours at a local university (MiamiDade County Public Schools 1997e; Miami-Dade County Public Schools 1998a).

According to the District LEP plan, the principal is directly responsible for making sure that the requirements are fulfilled and that teachers actually use ESOL strategies when LEP students are in the class. In addition, each year a random sampling of schools and students is selected for monitoring by district staff, as well as schools reported as having implementation difficulties. ${ }^{52}$ The District Plan requires noncompliance areas to be reported to the Region Superintendents and the findings of the reviews are discussed with district staff. The school administration can request technical assistance to develop a corrective action plan (Miami-Dade County Public Schools 1995b:19). 
Although teachers are supposed to be evaluated once a year, teachers in both schools said these class evaluations appear to happen rarely. When they did happen, as per union contract provisions, teachers were told in advance of the date of the visit and were able to prepare for them. It appears that the monitoring was done more at a bureaucratic than at a practical level. During my two years of fieldwork in the schools, I heard about these evaluations only twice. The first time was when I asked teachers about the subject. The second time was at the end of the 1997-98 school year, when the random selection monitoring process was in progress, and King's ESOL department head was given extra time out of class in order to update LEP student records.

Furthermore, implementing these rules in schools that register new foreign students practically every single day of the school year is difficult, particularly when these schools are already functioning over capacity and are already dealing with problems typical of other inner-city schools such as poverty and safety issues. As one ESOL teacher explained to me:

Some teachers do use (ESOL strategies), and some don't. The other day, a science teacher came to me and was very upset because he had just gotten an LEP student, ESOL I, Hispanic, in a class with forty students already, and he didn't feel like he could help this student and change his teaching style. He already has a lot of discipline problems to deal with. I used to think teachers didn't care, but now I feel that teachers also take a lot of abuse from the system, the content teachers. English teachers used to have less students in a class, because of the essay requirement, ${ }^{53}$ but now this is gone. ESOL teachers are supposed to have between 18 and 20 students per class. By this time of the year (October), I already have 27, because they keep coming in, and the classes start growing. Content teachers have around 40 students in a class. Sometimes they teach in the auditorium, and then they have tons of students, and there is no way you can give anyone attention like this. In the end, the students are the ones who end up shortchanged. (ESOL teacher, King High). 
To have a biology teacher provide comprehensible instruction using second language strategy, mind you, is very difficult at the secondary level. It's like anybody trying to explain to us anything in German right now. No matter how smart we think we are, and how good a teacher we have in front of us, it's difficult to get that sophisticated content through the use of strategies and visuals and a cooperative group, because the teacher, in the department there is no biology teacher who is bilingual. And so you've got to go with it, the subject being taught in English with ESOL strategies. And we provide training for those teachers. (Spokesperson for Office of Bilingual Education)

In general, for both of these schools, comprehensible instruction at the implementation level meant either that a class was taught in both English and the student's language of origin (BCC), or the requirement, not always met, to use ESOL strategies. Unlike Spanish, Haitian-Creole is not a language known by many nonHaitians. As a result, BCC teachers for Haitian students were Haitians. The principal at King High does not have problems recruiting Haitian teachers. The school has had a large Haitian population for more than ten years and Creole-speaking teachers contact the school. Northern does not have such a large Haitian population, although it has been increasing in the last years. Northern has to recruit its Creole-speaking teachers, and last year almost lost one of its few Haitian teachers who had not met the META training requirements.

\section{Assessment of LEP Students}

The following sections describe findings regarding the manner in which these schools interpret and implement policies concerning LEP students. The focus is on the people who are responsible for actually implementing these policies and their understanding of these policies. 
Students "trickle in," registering in these schools all year long and the population in both schools has a high mobility rate. Compared to the mobility index ${ }^{54}$ of 36 for high schools in the county, King High's index in 1995-6 was of 51, and Northern High's was of 41 . The following year they were 52 and 39 respectively, compared to 34 in the county. According to Northern's registrar:

We have students coming in all year long. Many students are coming without their parents, they live with relatives or friends of the family. Sometimes the whole family lives with other relatives and then they move, or the student doesn't get along with the relatives and moves in with other relatives.

The registrar's description appeared to be quite accurate. Regardless of school calendars, at any given day I could see lines of students accompanied by family members or guardians registering at the main office of the school. Schools are required to offer assessment of LEP on the school premises. ${ }^{55}$ Although there was an option for parents to choose a regional assessment center that offers additional services, very few parents or guardians chose this option. A large number of LEP students came to register accompanied by either a family friend of a relative who is not a parent. This happened because many students lived with friends or relatives who were not their parents, because parents who were illegal immigrants were afraid to come to school, or because parents could not afford to miss work. ${ }^{56}$ Consequently, counselors and teachers spent a considerable amount of time during the entire year testing new students and arranging class schedules. Typically, the ESOL department head did the testing of incoming students, and counselors did the class scheduling based on information collected by the registrar from students' transcripts. ${ }^{57}$ 
The head counselors had smaller caseloads and at Northern, the counselor who was testing chair had 450 counselees. The other counselors had approximately 600 to 700 students in their caseloads. Such numbers made requirements to call an LEP committee meeting for placement decisions seem quite unreasonable in view of counselors and teachers who already felt they were "spread too thin".

M-DCPS fits the pattern described in the literature (Fleischman and Hopstock 1993; Zehler et al. 1994) regarding determination of LEP status. English language ability is measured through a mixture of home language surveys and oral proficiency tests. The ESOL chair applies the Dade County Oral Language Proficiency Survey (DCOLPS). According to teachers who applied them, this takes about an hour. If the student knows little English, they finish fast. The more English a student knows, however, the longer it takes. Students, in grade 4 and above, who achieve at the "independent level" (ESOL V) are then tested on the Metropolitan Achievement Test (M.A.T.), $6^{\text {th }}$ edition. Students who test below the $32^{\text {nd }}$ percentile in both the reading and writing components of the test are considered LEP, while students scoring below the $32^{\text {nd }}$ percentile in either one of the components should be referred to a LEP committee to confirm LEP status (Miami -Dade County Public Schools 1995). During my fieldwork no one ever mentioned cases where this actually happened, indicating that the person who applies the test (usually the ESOL department head) generally makes the decision.

ESOL department heads at both schools expressed frustration at the assessment instruments used by the district. They complained that the DCOLPS is not a reliable instrument and that it goes against common principles in language testing. "There is no 
rhyme or reason for anything in that test; questions wander from one subject to another and are out of context."

A spokesperson from the Office of Bilingual Education says the test is reliable. However, they are in the process of changing it because although it is easy to administer, the scoring is very tedious. Each response has to be assessed in five different categories, and then computed into a score. Another problem with the DCOLPS is the fact that the same test is used every year to re-test students until they exit the program. The use of any of the commercially available language assessment tests would be more costly to the district. According to the spokesperson from the Office of Bilingual/Foreign Language Support at M-DCPS, the County tests approximately 100,000 students a year between new entries, updates, and exit tests, justifying the use of a "homemade" test.

The MAT, on the other hand, was considered too difficult for most students. According to one of the ESOL department heads, only about two percent of the students tested are able to score above the $32^{\text {nd }}$ percentile, theoretically requiring a LEP committee meeting, or continued assignment to the ESOL program. According to one teacher, a large number of non-LEP students in the school could not make the $32^{\text {nd }}$ percentile cut either, making the requirement unfair for LEP students. In practice the tests are used in part for assessment and in part to satisfy the legal requirement: both ESOL department heads interviewed said they also rely on their own experience and judgment when deciding about student's placement. One of the ESOL department heads requested and received a set of the IDEA test (a commercially available test the teacher believes is more reliable) from downtown, and used it as well. 
The requirement concerning LEP committee meetings are another source of dissatisfaction for school staff. ESOL department heads have teaching obligations as well, and have to use their planning periods for both functions. ${ }^{58}$ The District LEP Plan requires meetings of an LEP committee for decisions on student placement, exit from ESOL program, and post exit reviews. The committee is "a group composed of the ESOL teacher(s) and home language teachers, and an administrator or designee plus guidance counselors, social workers, school psychologists or other educators as appropriate for the situation." (Miami -Dade County Public Schools 1995:Chapter 6A-6). The District LEP plan also requires parent(s) to be invited and the school to keep a record of parent contact (Miami-Dade County Public Schools 1995b:8). Schools are also required to provide an interpreter for parents, if necessary.

In practice committee meeting requirements in schools as overcrowded as those in this study are merely another formality since a decision usually has already been made by the person who knows the case. There are no days set aside in the school calendar for these meetings. At King High the school holds what an ESOL teacher described as "mass committee meetings, when the people who are supposed to be in them alternate and step in and out of them, juggling the meeting with their class schedule. Sometimes the counselor is familiar with the case, many times they are not, if they have not had the opportunity to interact with the student".

The Consent Decree also requires students who exit the ESOL program to be followed for the next two years. Reviews should take place automatically at the student's first report card and semi-anually during the first year after exiting, and at the second year after exiting. Any consistent pattern of under performance on appropriate test and/ or 
grades should result in the convening of an LEP committee with parental participation to assess the student's need for additional appropriate programming as ESOL or other needed programs. The decree requires an "appropriate LEP student plan" in writing, for such students, to be maintained in the student's file, and this plan needs to be reevaluated after one year and each year thereafter as necessary. Students who have exited the program but are reclassified as limited English proficient can be reported in the ESOL program for funding for an additional year, or extended annually for a period not to exceed a total of six years. In addition, lack of ESOL funding eligibility does not relieve the district of any obligation to provide appropriate services to LEP children beyond the six years of State funding for ESOL programs.

M-DCPS follows the performance of its LEP students with indicators such as grades, conduct, effort, behavior referrals, and absenteeism. When more than three of the seven indicators signal that a student is failing, a meeting of the LEP committee with the parents is required. However, "What happens in these meetings is more of the same: we recognize the student is having problems and talk about it, but there are no mechanisms in place to help them" (ESOL teacher, King High). Since teachers and counselors feel they have nothing to offer, they are reluctant to ask parents to forego work and come to school to attend these meetings. One teacher told me she informs students about the meeting, telling them parents are welcome to join, but does not pressure them into coming. She sees no point in bringing parents to such meetings.

The State allows LEP students who have been receiving services in an approved LEP program for fewer than two years to be exempt from participating in the state wide assessment program $^{59}$ (Miami -Dade County Public Schools 1995: appendix B:117). 
Students are not exempt from meeting the standards set in these tests, and the county suggests schools use alternative methods of assessment to determine levels of competency. In the schools I observed LEP students were not tested for content areas in their native language. When I inquired about alternative assessments for incoming LEP students' knowledge in content areas, the answers were negative. The only exception is a math placement test, given to students when they come to the school to register. The test had few written instructions, in English, and some of the problems were presented both in the American way and the European style used in many Central and Latin American countries. Students were given no time to prepare or review for the test because usually they were given the test when they came to enroll. Whenever I watched students taking the test at Northern High, for example, students were neither given a dictionary nor a quiet place to work, taking the test in one of the available tables in the middle of the main office.

Due to the high number of levels offered in every core subject for each grade, it was clearly impossible to establish BCC classes for every single level of content area classes a high school normally offers. Counselors know that the requirement to use ESOL strategies in the classroom is frequently ignored, either because teachers are overwhelmed with discipline or other problems, or their training in these strategies was not effective, or they lack the will to use those strategies. As a result, the process of subject selection for LEP students in levels I and II is almost automatically restricted to the few BCC classes offered. These normally include Algebra I (parts A and B, both required for graduation), one Biology course, and a Social Studies course. In fact, eligibility for bilingual classes also meant automatic exclusion from the more prestigious 
honors and advanced placement classes, which were not offered in BCC. With the few exceptions that I shall discuss later, students who arrived in the U.S. with little English were placed in these basic classes, regardless of their academic aspirations and actual knowledge of the material.

Many practices in these schools appeared to be in contradiction with District policy, which asserts "the need to exercise special care to ensure that a student's limitation in ability to communicate in English is not a factor in determining the student's ability level." (Miami-Dade County Public Schools 1995b:7). District policy also mentions the need to pay "special attention to placement of high performing LEP students in honors, college preparatory and advanced placement courses." (Miami-Dade County Public Schools 1995b:13)

One of the new counselors at Northern explained what she had just learned about BCC placement:

Pretty much based on what Jane (the registrar) gives me, I go by that. In terms of which level to put them, usually, unless we have further information, they are put into a regular class, and the teacher is the one that will refer and say, well, I think this kid is advanced, more advanced and should be in so and so, and that's how we determine, pretty much, where they go, what level.

A similar comment was made at King High:

Students who come in with a more solid background would still be sent to BCC classes for the first two years. Especially the Haitians, they don't question the school's authority. I don't remember any cases like that (of Haitian students not going to the BCC classes offered). (ESOL teacher, King High)

In interviews with counselors and assistant principals, I was told over and over that exceptions to this practice would occur only for a very small number of students. 
This was particularly true for Northern High where the existence of an academically selective Magnet Program, the International Baccalaureate/International Studies, brings students from outside the boundaries of the school. Counselors say that students in the regular program in the school are allowed to attend some of the same advanced classes offered to the I.B. students. However, the person who enters the data in the computer (who actually places students in specific classes) told me that in general, "we try to keep them separate, you know." In this way, Northern fills the higher track classes that give the school prestige with a majority of students recruited outside of the school's feeder pattern. Because of the specific requirements to "improve racial balance" that apply to Magnet programs and the exceptions allowed, the program enrolls 68.4 percent non-black students, and 31.6 percent Black. Magnet Program students are not disaggregated in School Profile statistics (Miami-Dade County Public Schools 1997c). Consequently, the school's results on indicators such as the SAT, College Board SAT, ACT Assessment, and advanced placement examinations are higher than those of King High, in a sense concealing how the majority of students in the school are really faring.

According to Mr. Duvall, a Haitian counselor at King High, the perceived educational disadvantage of immigrant students is only true to a degree. Haitian students arriving now have been suffering the consequences of the instability that has seriously affected the functioning of schools in Haiti. Some students however had attended private schools in the last few years and were still able to continue their education. Schools in this study, however, were not careful differentiating among these students and some of the counselors assumed that all Haitian students coming in to the school system "have 
had less formal education than they would like to think they did" (Counselor, Northern

High).

A lot of them have not been in school at all. The district places them by their age, as opposed to their literacy, and that is a problem. Not that they don't not just know English, but they haven't been in school. And because they are sixteen, we take them. But we're not set up that way. The school system is not set up that way. (Counselor, Northern High)

The district offers a program called New Beginnings for high school age students who are illiterate or are working below Middle School level in their own language. Initially students were given high school credit for New Beginnings courses, so that students could graduate "in timely fashion" (in terms of their age and/or number of years spent in high school) ${ }^{60}$ A veteran math teacher who is now a counselor explained what happened:

You're supposed to be helping them fill in the gap that's the whole purpose of New Beginnings. But they (the county) kept insisting the students had to get high school credit while they are doing it. And that's just absurd because it doesn't work in math, math is sequential. You'll not help them if you give them credit for IA (Algebra), because IA says you got the pre-algebra skills, basically, you've learned to do simple equations. But they are counting on their fingers, adding still. And that's what they've accomplished, and learn to multiply and divide, you know those kinds of things, it's not helping them. I think this year they've finally got the right idea. They are giving elective math credit. So we can call it consumer (math) and that's what we will be teaching them to do. So they will be ready when they come out of New Beginnings to approach the prealgebra, otherwise you're doomed.

In contrast to the New Beginnings students, those who do come "equipped" as some counselors put it, need to be very assertive if they want to be placed in classes that are appropriate to their level in their native language. In the specific case of math 
classes, placement practices appeared to vary from one school to another, reflecting different perceptions of students' background. While at Northern, the assistant principal told me that it had never actually happened that a student was ready for a more advanced course than those offered in BCC classes. At King, both Ms. Bernie and Ms. Briggs (a veteran counselor) gave me a different picture: "They come in all varieties, just like students from other schools, from other parts of the country. Some of them are very good in math."

Ms. Bernie had this to say about students' math placement:

They are restricted for $\mathrm{BCC}$, but many of the students, if they are good, and they knew math, then they take it in English. And you would be surprised at how many have done that and done very well. If their mathematical level is there, then we put them in the math class and we try to pair them with a student, or stuff like that. They're not limited to taking that (BCC), but there are so few that really can jump that high, but there are people who do this.

Since Dade County does not officially offer academic and vocational tracks, in theory students are allowed to pick the courses they want, and therefore, students supposedly have control over their opportunities to learn. In practice, classes that offer increased opportunities to learn, such as Honors and Advanced Placement, require a teacher's recommendation and counselor approval. As a result, teachers and guidance counselors are expected to observe the variations in achievement and assign students to appropriate courses. This is not a simple task for teachers whose classes have more than 35 students and counselors have more than 600 counselees, many with serious personal and social problems counselors are also expected to address. 
Counselors and teachers in these schools perceived policy as allowing students to receive high school credit for "non-high school" level courses such as math courses that are below the Algebra I level, for example. Many expressed concerns that these educational practices actually hinder students' preparation for a college education. In some counselors' views, the New Beginnings program was one example where this was happening, until the district stopped giving high school credit for work done in the program.

Another example mentioned in both schools was the practice that requires students who exit the ESOL program to take grade level English courses. This is supposedly a result of the fact that the Consent Decree establishes that ESOL classes must provide students with Language Arts credits. Students cannot graduate from high school with less than English IV (twelfth grade English). The promotion of a student from ESOL III or IV to eleventh or twelfth grade English classes (English III or IV) is based on the assumption that there is correspondence between the curriculum goals in ESOL and in regular English classes. Agreeing that there is correspondence between the curriculum goals, ESOL teachers and counselors were displeased with the way the mainstreaming was done. ESOL courses teach the basic English grammar and also reading and writing skills that many students lack in their native language. ${ }^{61}$ Particularly for the Haitians who, in general, choose not to receive language arts instruction in their home language, and even when they do, it is not at high school level, teachers and counselors find the assumption that skills are transferred from one language to another not realistic. ${ }^{62}$ There is no transition between ESOL classes and grade-level English, 
regardless of the grade students were enrolled in. Students who exit ESOL in tenth grade, for example, are enrolled in eleventh grade English.

Counselors in both schools complained about this policy, saying it is unfair to place a student who just exited ESOL III or IV in an $11^{\text {th }}$ or $12^{\text {th }}$ grade English class, because it is too hard for them. Counselors usually try to place these students with an understanding teacher. This strategy "sometimes works but some teachers try to get the students back into the ESOL program, because they already have too many (discipline) problems in their classrooms and don't want to deal with these students" (Counselor, Northern High). District implementation requiring schools to give Language Arts credit for ESOL courses, as is the case for students receiving $11^{\text {th }}$ grade English credit for an ESOL class creates a problem. These students are promoted to classes that deal with material for which they are not ready yet.

This calls into question the content of the ESOL curriculum, the appropriateness of the individual LEP plan, the adequacy of the program exit process, the utility of the inservice university META training in ESOL strategies, as well as the effectiveness of monitoring and teacher evaluation processes.

When teachers get those students they don't have time to deal with their specific needs, so they reward compliance and being there, and they give students passing grades. They are not looking for accuracy. Everybody is involved in a frustrating situation. High school teachers, a lot of times, especially area teachers, feel frustrated that they were supposed to be teaching at high school level, but are not. They have to adapt and teach at a much lower level than what a high school teacher would expect. The good teachers will go out to Drago and Get Smart (two local teacher resource stores), and get resources and come to the level of the student. Still, they are supposed to prepare the students to take the SAT's and HSCT's. So they have to find a way to teach at the students' level and still get them to pass the exams. The bad teachers, those that don't care, just keep teaching from the textbook which is theoretically appropriate for that 
level, and they make students answer questions 1 through 5 and fill in the papers, and they go home and don't care.' (ESOL teacher, King High).

In addition to overcrowded classrooms, discipline problems and lack of teacher preparation to deal with language minority students in the high school setting, some students also face the issue of sheer lack of teacher dedication. This was illustrated by comments I heard from several counselors that "Too many teachers come here just to collect their paychecks and don't really care" (Counselor, King High).

All counselors mentioned the unreliability of standardized test results for minorities, saying they do not use SAT results, even when available, as placement information, since too many of the students in the school do not test well. In both schools it was clear that the alternative forms of assessment of students' knowledge suggested in the literature, such as oral assessment of subject knowledge or assessment in native language (Zehler et al.1994), are not viable options given the size of the counselors' caseloads. Large caseloads, and the resulting paperwork required in a school district as big as M-DCPS reduce the time for personal interaction, leaving counselors with very few sources of information to place these students. ${ }^{63}$ In this context, placement of LEP students (as that of students in general) followed a somewhat routine pattern: LEP students in ESOL I and II are placed in the few basic classes offered in BCC (Environmental Science, Earth and Space Science, Algebra I parts A and B). Students at the ESOL III and IV classes were also placed in classes counselors hoped would be easy for them. This was perceived as an effort to help them "survive" in a class taught in English with their limited English skills. At King I observed counselors encouraging students to take harder courses and try to get better grades. 
Several counselors made similar comments regarding the amount of time available to actually guide students.

You get to deal a lot with seniors. ${ }^{64}$ Your juniors, $9^{\text {th }}$ and $10^{\text {th }}$ graders really get the bad end. You end up, specially the $9^{\text {th }}$ graders, only probably getting to see the ones with the problems that are made public, you know. Some of them are not rocking the boat, it's unfortunate, it's not what we would like to have, but it's all the paperwork that's involved with our job, that keep us from getting to the students individually. (Counselor, Northern High).

Counselors in both schools commented that there is not enough time available to deal with all their students, and they have some students who they only see on subject selection day. Despite the similar caseloads for counselors in both schools, Northern's counselors complained of lack of time to deal with students more often than King's. Although both schools have rules requiring students to make a request for a visit with the counselor and then wait to be called in, at King High there was more openness and willingness to bend the rules and talk to students. At King there was a feeling that counselors were more available to students: counselors doors were often open and counselors would volunteer to help students not in their caseload. From a practical point of view Northern students faced more physical barriers (a counter and several secretaries) on their way to counselors than did King's students, who could easily walk to the door of any counselor.

\section{Placement: the meaning of the different learning sequences}

Even though practically all those interviewed mentioned the high aspirations of immigrant students, many of these teachers and counselors also believe that foreign 
students are educationally disadvantaged. Students who bring documents from their country of origin proving that they have taken equivalent to those offered in $\mathrm{BCC}$ could, theoretically, be placed in higher level classes. Counselors, nevertheless, usually try to convince those students that it is in their best interest not to do so because their limited knowledge of the English language will be a problem. The fact that teachers are required by law to use ESOL strategies in order to accommodate the needs of LEP students is not taken into account for placement purposes. In these schools, in general, it was presumed that the requirement is ineffective. This informal policy clearly contradicts the ideology of opportunity and high standards promulgated by the district. On the other hand, the advice seems to make sense in the context of already troubled, overcrowded inner-city schools, where counselors know that the chances of these students meeting dedicated teachers with the time and energy to help them are limited, at best.

In one instance, a Hispanic boy came into his counselor's office complaining that his math class was too easy. The student asked to be placed in a higher level class, explaining that his low results in the pre-test were due to the fact that he had taken algebra the year before last, and last year he had taken geometry and trigonometry. The response he got from his counselor was "But you don't know the material in English, and you will be tested in English, so it's better for you to take it again, but if you really want to change, go and ask the teacher to give you another test."

When I asked another counselor whether language could be an obstacle to placement in honors or advanced placement classes, he replied: "It might, but if you can't speak the language, how can you go to an advanced class anyway?" 
Counselors and teachers accept the unspoken rule that LEP students are placed in the least demanding classes, where "opportunities to learn" (Stevenson, Schiller and Schneider 1994) are restricted. At the same time they are quite aware of the impact of different types of classes on future careers. Counselors are well informed about what colleges "are looking for" in students' academic curriculum. One counselor reported receiving a letter from a state university informing the school that "students who take only regular classes do not even need to apply, regardless of their grades. Only those taking honors and advanced placement courses should apply." 65

Ms. Sanders, a counselor, when questioned about the differences between children who grew up in the school system and the recent immigrants, told me:

I don't think it is so much kids that have been in the system, as it is parents' background. I mean, my niece goes to Miller City High School (not a real name). Her parents are college graduates. They know what they have to do to get in, they know what they have to do to stay in, and they know what courses and grades she has to get in a much more competitive Florida, for her to get in. She cannot bring home C's in regular classes at Miller High and expect to go to Florida State. They know that, they told her that. She doesn't need a silly high school counselor to tell her what she needs to do to go to college. It's been drummed into her head ever since. But that's because they are intelligent people, and they understand that you have to have a certain grade if you want to go to college... I mean, they get the whole picture, it's not the definition of American born, it's the background, sophisticated background of the parents.... Many parents think it's just a progression after high school, that it's a natural progression, you go to High School, you go to college. They don't understand anything about qualifying."

Counselors often allude to Haitians' lack of experience, not only with formal education, as in their lack of study skills, but also with the intricacies of the educational system. Despite that, counselors in both schools are impressed by the Haitian students' 
high academic aspirations. "They all want to be doctors and lawyers, but they just don't know how" or " everybody thinks they are college bound" were frequent comments.

Many of the counselors consider these aspirations unrealistic. Although Haitian parents are perceived by school staff as sharing their children's ambitions, counselors do not perceive parents as being able to provide support for students. Several incidents mentioned by teachers or counselors reflect the lack of understanding between Haitian parents and the school staff. Ms. Sanders, a few days after telling me about her niece, reported this incident to me:

The mother of an LEP student who just started ESOL III and is now in regular (not BCC) classes came to complain about her daughter's grades. She felt C's and D's are low. She has no clue how hard this course is. She probably never took a course that hard in her life. I told her, through the translator, that the girl is doing GOOD, that for someone who just got into ESOL II these grades are great!

Counselors were aware of the gap that results from the process of Americanization of immigrant students and their parents attitudes and values, either because of their own experience with students or because they attended a "multicultural sensitivity" training seminar. From what some of them described to me, however, it seems that despite their good intentions, in some cases such seminars actually reinforced some of the negative perceptions teachers and counselors may have about Haitian parents as authoritarian, extremely strict and not able to communicate with their children.

Although her evaluation that a student in ESOL III lacks the necessary English skills to succeed in a mainstream high school Biology class is probably correct, her response does not provide any opportunity for the student to improve her grades. Her response also takes away the legitimacy of the mother's concern. Haitian parents in 
particular are perceived as too strict on one hand, while too reliant on the school's authority on the other.

They depend on the school to tell them what's good for a student. So parents usually accept the advice, you know (Counselor, Thomas High).

They believe that the school does the school job, and the parent does the parent's job. They tend, they come and they check on the students, but they tend to, if you were to say, well, this student should go to ESOL II they don't usually get involved, ESOL II is what the student gets. There's not a challenge in that way, with immigrant parents (Counselor, Thomas High).

Counselors and teachers commented on the problems between Haitian children and parents. Several of them had learned something about Haitian "prevalent" attitudes concerning children in sensitivity training workshops. But most counselors refer to these parents' expectations as unrealistic. Their perception of the generational dissonance between the children's desire for an American way of life with its entitlements and freedom is biased on the side of the children. "They (the parents) expect the kids to go home after school, do chores, do homework and go to sleep. Many don't let their kids watch T.V. or talk on the phone or go out at night, especially the girls." Despite these views on Haitian parents' attitudes, when discussing education in general the same counselors would have a more critical stance regarding values such as consumerism and immediate satisfaction and how they hurt children's relationship to education.

Counselors in both schools frequently mentioned that Haitian parents tend to punish their children too harshly. One counselor reported having parents in her office telling their own children that "they brought the kid into the world, they could take them out," explaining to me that Haitian parents feel they have the right of life and death over 
their children. These perceptions, whether reflective of a majority of the Haitian parents or not, create an added impediment to school-home communications. Counselors told me they only contacted parents about achievement problems in school after consulting with the students, for fear of putting them at risk of physical abuse at home. This legitimate effort to protect the children not only undermines the authority of the parents, but also makes parents suspicious of the school covering up students' misbehavior or lack of effort, further alienating the parents from the school.

Counselors are aware of the high aspirations of immigrant students and their parents, and they also realize that many immigrants, as well as poor African-Americans, lack the cultural capital required to make it in the system, or what Portes and Rumbaut call "learning the ropes" (Portes and Rumbaut 1996). With few exceptions, however, counselors and the school system in general do not consider it their job to "teach those ropes." Within the meritocratic ideology defined by educational policy and the de facto tracking system, it is legitimate to help only those students who seem "promising." At the same time the majority go through a system that offers learning sequences with "watered down" course content.

Particularly at Northern, where I observed students during subject selection week and also spent many days alphabetizing subject selection cards for the whole school, I was able to document a consistent pattern of placement of students in the least demanding courses. This was true for all students, except those in the Magnet Program. It is common for the high school counselors to place students in courses that are lower than the courses students requested, even when students have the teachers' recommendations. In several cases where students had selected honors classes, they 
were enrolled in regular classes. This is especially true when students were asking for placement in only one honors class and particularly for students coming from the feeder schools. When I inquired from the head counselor at Northern about the reason for this "downgrading" she explained that "Counselors know better, middle school teachers don't know about high school courses."

The district allows parents to override the schools' decisions regarding placement, even though this right is not really publicized. Northern implements a rule that students who choose to enroll in a class at a higher level than recommended forfeit their right to move out of that class. ${ }^{66}$ They have to stay in the class "for the duration." This rule keeps students who do not have teacher recommendations from attempting to enroll in higher level classes, by scaring them with the possibility that if the class proves too difficult, they will not be able to move back to a regular class. Failure in a class means the student does not get the credit, and, therefore, may not be able to graduate with their class. In the meeting before subject selection week, Ms. Sanders made a point of reminding the newer counselors of that rule, and making sure that it is enforced.

By the end of the first week of school in the 1997-98 year, one of the dozens of slips on the table of a new counselor at Northern, from a $9^{\text {th }}$ grader, read: "I SHOULD BE IN ALL HONORS CLASSES." At that point the counselor was only dealing with emergencies, such as students who had registered for a course counting on taking a prerequisite during the summer and had failed the summer course, thus ending up in the wrong class. The case of the student requesting the honors classes was left for later, meaning that if the student actually got transferred to where he or she wanted, it would 
already be at least by the third week of school, one third of the nine-week grading period already gone.

Alternates and electives are yet another example of the unspoken way curriculum tracking occurs. An examination of the subject selection cards yielded a pattern where students who are in honors classes and advanced courses take academic electives such as foreign language, debate, or an extra social studies course. In contrast, the majority of students in regular classes are enrolled in electives such as 'Health and Nutrition' (which according to Ms. Jones, is just a new name for the old cooking class and "students take it because they want to eat something good"), Family Dynamics, or Weight Lifting (I and II). Thus the gap between what "promising" students and the others are learning in school becomes larger each year. Not only are some students getting a better education in their core courses, they are also getting educated in their electives, while the rest of the students are simply collecting credits toward graduation. ESOL students in particular are steered towards classes considered less demanding, meaning non-academic electives. This is conceived as a benevolent way to lessen the burden on the students, help them pass their core classes, and improve their grade point average.

In the core courses (math, English, science, and social studies), once a student is placed in a learning sequence, it becomes almost impossible to change into a more advanced sequence. Every year the gap between what is taught in the regular and the accelerated tracks increases, especially in math and science. For foreign students who arrive without a detailed knowledge of how this system works, by the time they reach eleventh or twelfth grade and find out about the requirements of the state university system, it is very late. These students' only chance is to complete remedial work at a 
community college. This means that students will need to pay for a course that was offered free at the high school and use up the financial aid needed for college level work. For many LEP students who manage to graduate from high school even the community college is beyond their academic limits, according to King's ESOL department head. She heard that from a representative of the local community college who told her so in a meeting she described as "very depressing."

Although counselors know about college requirements, I rarely heard anyone mention to a student taking a certain course that this would limit their future opportunities for college acceptance. Both LEP and non-LEP students more often than not take the least demanding course load, yet one hears very little being said in terms of the consequences of these "choices" for college acceptance.

This is a minority school anyway, and in the whole school system all minority youth has problems in education, we know that. When Haitian students identify with African-Americans, they get in trouble, because they integrate into the wrong group and adopt a negative approach to education. (Counselor, Northern High).

During the 1996-97 school year, only one counselor in the school spoke French, Haitian-Creole ${ }^{67}$ He expressed some awareness of the issue of immigrant students' assimilation into the oppositional culture of the African-American majority. His conception of what is happening to the Haitians in the school includes elements of Portes' ideas on segmentary assimilation as well as Ogbu's concept of negative academic orientation.

This counselor's concern with the downward assimilation of Haitians at Northern led him to attempt to convince the principal to let him be the counselor of the LEP students, bypassing the system of distributing students to counselors by dividing the 
alphabet. He also wanted to hold a separate Open House night for LEP students and parents. Both ideas were vetoed by the principal under the argument that they were "discriminatory." At King High recently arrived Haitian students were not assigned to the two Haitian counselors, unless their last name happened to be in this counselors' range. The principal, however, did allow the ESOL department to hold a separate Open House night for ESOL students. Both schools had separate days for subject selection for LEP students, but that is not considered discriminatory. This separation prevents interaction between LEP students and those who may know the system better and who could, at least in theory, provide LEP students with some help that the counselors have no time to give. At Northern, with the addition of the ninth grade in the fall of 1997, the ESOL classes were transferred to the added portable classrooms, adding an element of physical isolation to the linguistic isolation of LEP students. In the fall of 97 an African-American principal replaced Northern's principal. A few months later he announced he would change the location of ESOL classes back into the school main building for the next school year.

In both schools the majority of all students (LEP and non-LEP), are enrolled in the least demanding math and science classes. For example, at King High, there were two Honors Biology I classes in contrast to nineteen regular Biology I classes. There were three Honors English I compared to fifteen regular English I classes. Regular classes sometimes (although not always) enroll between 38 and 42 students while the few honors and advanced placement classes usually enroll no more than 20 students. Although the district establishes class size limits, these are not calculated for each individual class, but 
as averages for subjects, allowing for basic courses to become particularly overcrowded.

The more advanced a course, the smaller the student-teacher ratio.

In science the vast majority are enrolled in courses such as Marine Biology, Earth and Space Sciences and Environmental Sciences, which are non-sequential courses at basic levels. Students receive three credits in science, but there is no accumulation of knowledge that leads into a higher understanding of science. Only a small minority takes courses that belong in sequences that increase their chances of college acceptance, such as Physics and Chemistry. A review of the course credit analysis of 30 Haitian students in the project's sample pointed in the same direction. Even those who had completed Biology in $8^{\text {th }}$ grade with a B were not enrolled in Chemistry. Despite the fact that the curriculum bulletin at Northern lists Biology, Algebra I, and teacher recommendation as pre-requisites for Chemistry, one counselor usually told her students that they should have at least Algebra II to take Chemistry. Officially, Algebra II is only required for Honors Chemistry. When I checked this with other counselors, it appeared that this specific case is an idiosyncrasy of one particular counselor. However, the message that many courses offered are "hard" is constantly repeated, and most students tend to stay away from them. A common comment at Northern is "the kind of students we have here are not college material." Although the state collects information on what happens academically to its graduates, when I asked counselors, I was told the information did not exist. Counselors at both schools estimated the percentage of students who go into college somewhere between 12 and 20 percent. $^{68}$

While M-DCPS affirms that "we don't track students", incoming ninth graders entered these high schools already tracked. The courses they took in $8^{\text {th }}$ grade, 
particularly in math and science, are part of sequences that will lead to very different opportunities to learn during high school. At Northern, where I had access to the incoming ninth graders' subject selection cards, I observed a pattern of downgrading the placement of students who had recommendations from the middle school. However, students arriving from other countries and who are qualified as LEP and entitled to bilingual education are the ones with the most limited course choices. In both schools, these new immigrants are entering schools where only a few students are offered opportunities for the kind of courses likely to lead to higher education and good jobs.

Despite complaints about the difficulties of implementing several of the policies and an awareness of the inappropriateness of standardized tests for minorities, the narrative of most counselors never questions the existence of tracking. The assumption that different levels of course offerings is the only way to deal with variations in ability is taken for granted, and counselors genuinely believe that they are serving students best interests by helping them find the path of least resistance towards a high school diploma.

\section{Beating the odds: what does a "high achiever" look like?}

Counselors take pride in helping students they perceive as highly able and motivated. Many of the counselors interviewed, particularly at Northern, at one point or another told me a story of an exceptionally motivated student they had helped.

I had this one student who came in as an ESOL I and ... was already in Algebra II. He walked into this building and it's like I want to go to college, I want to do this, I want to do that, I want to get out of ESOL as soon as possible. (...) I had to sit with the teacher, and she said: "No, he has an attitude. He is very arrogant." And I said, well, you have to understand, he is probably coming in with a very strong background, and he feels like these kids are pulling him down. And that was what the 
problem was, he was ready to move. He graduated with a scholarship to Miami Dade. Very good grades. And I knew, the minute I met him, I said this kid has the potential. You know, he wanted to be in the advanced courses from the very beginning. (Counselor, King High)

When a student manages to impress a counselor, the counselor usually tries to place the student in a class appropriate to the student's level and with a teacher likely to care about the student's progress.

I had a Haitian student who was in ESOL II or III, and was very good in math. So I sent him to Algebra I. The teacher, a very dedicated one, realized that he could go to Algebra II, but she said he needed to be in her class, because his English is not that good, and he needs attention. She wanted him in Algebra II, but only if it was in her class. We had to shift the kid's whole schedule around. So teachers complain that students are one day in their class and the next day they are somewhere else, but this is a trial and error process. (Counselor, Northern High).

This type of strategy becomes harder to practice with increased school overcrowding. Although counselors can make an effort to place students with specific teachers, at the beginning of the year many students are shifted to other classes, to help balance class size. This practice is called "leveling" and in the 1997-1998 school year, it went on for almost the entire first grading period. Thus a counselor has no guarantee that a student's schedule (and the teachers) will remain the same once the year begins.

The assumption underlying these "success stories" is that academic talent is a fixed trait that is immediately recognizable. Linguistic and cultural differences are not perceived as a barrier to recognizing talent. When I questioned Mr. Gray whether he thought LEP students were being tracked downward, his response was that "When you see the student in front of you, you know: there is not much science to placement. Most students have 
high aspirations, not that they want to study hard, but most of them want to go to college."

Mr. Gray expressed most clearly a sentiment that seems to be shared by some other counselors, although definitely not all. He considers it part of his job to be realistic and tell students about the world the way it is, that not all students can go to college and he would be doing a disservice to them by maintaining the illusion of college. This comment is all the more relevant in the context of a school environment where college is seen as the only positive, legitimate alternative and where the principal has assigned the Occupational/Placement Specialist to work with the school budget.

When talking about these "special" students, counselors usually mention a student's drive and persistence in asking to be taken out of ESOL. Depending on the student's ability to captivate the teacher or counselor, it can be either interpreted as "having an attitude" or as a highly motivated student. This is interesting considering the fact that Haitians in particular are perceived as docile and respectful of school's authority. While counselors appreciate how recent immigrants from Haiti tend to be "nice and polite," their perceived lack of assertiveness regarding their academic careers does not help their opportunities in school. ${ }^{69}$

Although never questioning the existence or the effects of tracking, the narrative of the counselors reflects frustration at the perceived lack of effective changes by the school district or the state aimed at improving student engagement and achievement. Counselors acknowledged that the constant changes in requirements (such as increased minimum GPA required for graduation, the requirement for Algebra I, and the five point rule $^{70}$ ) and changes in course names and sequences (such as the division of Algebra I into 
parts $\mathrm{A}$ and B) are confusing. During a meeting with the counselors to clarify the rules for subject selection for example, Ms. Jones joked: "Are you confused enough already?" However, this understanding is often not extended to the students, particularly the LEP ones, for whom these changes are obviously even more confusing. At times some counselors project their frustration on the students, accusing them of being uninterested, not "doing their homework" (meaning reading the bulletin and getting teachers" signatures where recommendations are needed) and even, in one case, of being "the dumbest group of kids we have ever had." 


\section{Chapter VI Discussion and Conclusion}

Federal and district policy rhetoric affirms a desire for equal opportunities and quality instruction to all students, including those with limited English proficiency. While asserting that "every student can learn given quality teaching," the reality dictated by the existence of extensive tracking, particularly in the core content courses, is that only students perceived as promising are placed in challenging classes with student-teacher ratios that allow for quality instruction.

In contrast to this high achieving minority, the vast majority of students (both LEP and non-LEP) in both schools suffers the consequences of an overcrowded system that lacks adequate resources for testing and counseling. The combination of tracked classes with limited resources creates an educational culture where access to higher level classes is carefully guarded. This in turn generates a huge disparity between students' aspirations and the level of work they do in high school. Such an environment constitutes a big enough obstacle to English speaking U.S. born minorities, such as AfricanAmericans. It is an even bigger obstacle to immigrant students who come here believing in the rhetoric of the "Land of Opportunity."

Educational policies state that schools are responsible for providing understandable instruction through either the use of ESOL techniques or the use of the native language. However, with a curriculum that offers such a variety of course levels, a staggering amount of classrooms and teachers would be required for a school to offer every student in ESOL I and II the opportunity to take each and every class through the required special instruction, $\mathrm{BCC}$. There is an absence of commitment to teacher use and 
to administrative enforcement of ESOL strategies, due to the constraints usually found in overcrowded inner-city schools as well as, in some cases, to lack of will to help "these people." In this absence, the policy establishing that no student should be deprived of comprehensible instruction at the appropriate level becomes inoperable. The fact that schools offer certain less demanding courses in the $\mathrm{BCC}$ format pushes the majority of LEP students at levels I and II to these classes, regardless of their level of knowledge. When students reach ESOL III and IV levels and are mainstreamed, they may be able to convince counselors to place them in the appropriate level. But then many teachers fail to provide these students with understandable instruction. Reasons for this failure range from being overwhelmed by large classes with discipline problems, or because their training in ESOL strategies was not effective, or out of sheer prejudice and lack of will. Schools simply cannot afford to provide comprehensible instruction through $\mathrm{BCC}$ at all levels for all students who need it, and counselors are aware that ESOL strategies are not used in a satisfactory way in mainstream classes. The counselors' decision to help students by placing them in easier classes makes perfect sense in the context, regardless of how much students may know in their native language. But the practice undermines LEP students' ambitions for higher education and social mobility.

Another obstacle in the achievement of equality of access to opportunities for LEP students results from certain elements derived from the policy. The district interpretation of policies establishing that students have to be treated "equally" lead to the decision that students need to be able to register in the school site. Paradoxically this results in an excuse to prevent other needs of these students (such as a more careful assessment of their knowledge using the native language, for instance) from being 
addressed. ${ }^{71}$ In the process of assuring "equality" LEP students actually loose access to opportunity. Another paradox is that while certain practices are considered discriminatory, as is the case of requiring registration at a central site that could specialize in assessment of LEP students, other harmful practices are commonplace. Examples of such practices that tend to isolate LEP students include the habit of assigning ESOL classes to portable classrooms outside the school building whenever a school requires them, or holding separate days for subject selection for ESOL students. This last practice in particular is relevant for the subject of tracking because it prevents more recently arrived immigrant students from interacting with students who might know more about the educational system.

In her attempt to explain why schools do not change, Oakes mentions the existence of "persistent and deeply rooted assumptions about human abilities and the role of schools in providing equal opportunity" (Oakes 1986:60). In my research, I have found two fundamental assumptions that underlie school counseling and placement. The first is the assumption of great variance in learning ability and these different abilities are better served by different course offerings. In fact, schools work on the premise that most students are simply unable to deal with challenging and advanced material. Although proponents of tracking assert that lower track courses prepare slower students for more sophisticated knowledge in the future, the way the curriculum is organized clearly denies this assertion. In reality the curriculum is organized in such a way that some courses belong to sequences leading to greater opportunities to learn (and to be accepted in college), while others simply provide students with credits towards 
graduation. A good example of this is the math sequence, where students can graduate with courses ranging from Algebra I to Advanced Placement Statistics. ${ }^{72}$

The second assumption under which schools work is that academic talent is immediately recognizable. Many counselors sincerely believe that they can reliably and validly identify, "the minute they walk through the door," those students who are outstanding and deserve to be placed in higher level courses. While most counselors behave as if these traits are inherent and fixed, observation and their comments reveal that "talented" students really present a particular form of cultural capital. In the U.S., assertiveness, expressing one's ambition, and knowing about the consequences of being placed in different learning sequences are the equivalent to France's linguistic capital and museum culture found by Bourdieu to count as legitimate cultural capital. It is this type of capital that is rewarded with placement in smaller and more challenging classes where students are offered the opportunities to develop the higher order thinking skills required for high status jobs. Conversely, politeness and respect for authority, common among Haitian students, are esteemed by school personnel but not rewarded academically.

These two case studies in this project confirm the fears expressed by Zehler et al. (1994) in their study of the assessment of LEP students. Classification of a student as LEP entitles the student to important special services particularly in terms of language instruction, but at the same time may exclude them from other opportunities. My findings indeed confirm that language limitation does limit students' future opportunities and, many times, unfairly exclude LEP students from more advanced learning opportunities.

My findings also support the assertions of Resnick and Resnick (1985), that, despite the rhetoric that emphasizes a comprehensive curriculum, in reality there is 
considerable tracking in the high schools, even when it is not formally labeled. The enormous variation in the expectations and standards enforced in the different levels of courses offered within the school points to the de facto maintenance of tracks. This study indicates that despite the assertions that "we don't track students," students are in fact being tracked. In addition, the lack of appropriate assessment for LEP students adds to overcrowded conditions and leads to placement decisions that rely on personal impressions obtained during brief meetings. These impressions will inevitably be linked, in some way, to ascriptive characteristics such as race and socio-economic background. In this sense, Mosca's (1939) ideas about the subtle ways in which dominant groups pass their privileges to their children continue to be true, despite all the legal and policy efforts to prevent it.

What this study also reveals is that the absence of formal track labels is particularly damaging to those students and parents who are not aware of the intricacies of the educational system and who come to this country trusting in decisions made by the educational system. Particularly for students arriving in the U.S. at high school age, by the time they find out that their high school diploma does not prepare them for college, or that they must first complete remedial work in community colleges, it is too late to be moved to better courses.

Despite these limitations in terms of access to equal opportunity, I found that the school atmosphere mediates, to a certain extent, between tracking practices and immigrant students. The pressure toward taking less demanding courses was stronger at Northern than at King, where the administration seems more understanding and supportive of the students and sets a different tone in dealing with them, at least at the 
level of counseling. One reason for this may be the fact that King High has no Magnet Program from which to draw students for its higher track courses. This forces the school to look harder into its own pool of overwhelmingly Black minority students to fill those limited spaces in the school's advanced classes. This finding raises validity issues regarding the interpretation of studies of tracking that aggregate data from different schools, where this level of data can be lost.

Schools are limited in the ways they provide opportunities for students by outside constraints, such as State and District policies and a general lack of resources. These constraints will be similar for schools within the same district. Other limitations are the result of within-school constraints such as a school environment resistant to offering certain minority groups (who may be the majority of students in a school) a better opportunity, due to (mis) perceptions about the groups' abilities. Therefore, as suggested by Pallas et al. (1994), to explain students' placements in different tracks one needs to analyze the constraints under which schools function, the school's own organizational processes, and how these factors interact with student characteristics.

Theoretically, the findings in this study support Saha's description of the role of schools as both agents of social mobility and social reproduction (Saha 1987). While the majority of students in these schools appear destined to social reproduction, those who bring the cultural capital required to impress the "gatekeepers" (in this case, counselors or teachers) are able to get the doors to mobility opened, or at least cracked. Thus, at any given point, a certain number of minority students make it into higher tracks and thus reinforce the myth of the possibility of social mobility for all, when in fact, mobility is only offered to a selected few. The contradiction between policy assertions that 
"everyone can learn given high quality instruction" (Office of Bilingual Education and Minority Language Affairs 1997) and the continued existence of tracked classes simultaneously supports social reproduction for the majority and mobility for a few. The rhetoric of equality addresses "how we think the world should be" while the existence of tracked classes recognizes a de facto inability, or lack of political will, of the educational systems to offer real equal opportunity. This contradiction is at the core of the issue of equality of educational opportunity.

The study also points to the existence of variations in what constitutes the required amount of cultural capital for a minority student to be considered a potential high achiever in each school. The issue relates to Bourdieu's insights on unequal selectedness (Bourdieu and Passeron 1977), regarding the relationship between the degree of selectivity for courses that offer highly valued cultural capital and the degree of competitiveness of a certain track in a given educational environment. The absence of a Magnet Program at King High makes their higher track classes less selective for LEP students. Although perceived by the school as a problem, because students from the feeder pattern who are perceived as having academic potential are recruited by schools offering "better" programs, this absence potentially benefits King's LEP students. Two important factors are the type of population that makes up the majority of students in a given school and whether the school has any programs to attract students from a different ethnic group. In such cases, these recruited students then can appropriate for themselves the higher level classes in the school, as is the case at Northern.

This discussion has implications for Portes' (1995) ideas on the importance of location for segmented assimilation. While it is true that immigrant youth living in areas 
where the majority of the population is characterized by "cultural inversion" and negative academic orientation might tend to assimilate into that group, when one looks at the process of distribution of resources inside the school, a different picture may emerge. Immigrant youth with little cultural capital entering a school whose population is mostly mainstream children might face tougher competition for places in higher track classes than they will in a "low achieving" school. King seems to exemplify such a possibility, while Northern, due to the Magnet Program illustrates a different situation. So despite the general tendencies in both schools to have very few higher track classes, LEP students appear to stand a better chance of placement in a higher track at King than at Northern. ${ }^{73}$

On the other hand, the issue of generational attitudes towards assimilation and academic orientation raised by Portes points in the opposite direction. Immigrant students and their parents come to the U.S. with high aspirations and a positive academic orientation. The data collected from school teachers and counselors, as well as that gathered by other researchers in the project working directly with the students and their families, points to a pattern of generational dissonance in terms of assimilation. When students begin to acculturate into American mainstream culture, one that is increasingly focused on consumerism and the immediate satisfaction of desires (Fjellman 1992; Steinberg, Brown and Dornbusch 1996), school personnel perceive parents' efforts to discipline their children as outdated and cruel. Often, they also consider parents' demands for higher academic achievement as unrealistic in face of the language, social and academic difficulties encountered by the students. This results in a situation where the school and parents send different messages to students regarding expectations in terms of achievement and behavior. The school "sides" with the students, expecting less of them 
and supporting their acculturation to perceived "American" values of freedom, individualism, and consumerism. Parents, on the other hand, cling to their traditional values of hard work and respect for parental authority. Thus, the adaptation strategy found in the literature to be most conducive to school success, that of accommodation without acculturation, (Achor and Morales 1990; Gibson 1997) is diluted by the school, further undermining the immigrants' chances of social mobility through education.

As a final remark, I wish to make clear that although I have called teachers and counselors "gatekeepers," I did not use the word in a pejorative sense. In general, the school staff I encountered were dedicated people with a genuine interest in the welfare of their students. Many mentioned the fact that they are "spread too thin" and expressed a wish that the school system would give them better means to achieve their goals. This is why I want to end with a comment I heard in similar form from many counselors

We treat them like anybody else. We put them in the pool and let them swim. Or try to swim. Or sink, you know, and so we're following that directory (...) A lot of those kids are set up to fail. But nobody hears us. Those people, who make the policy, most times have not even been in the classroom. Of course, there's no excuse. Everybody should be in school, everybody can learn. True. Given the right tools. 


\section{Notes}

${ }^{1}$ With the exception of some Asian groups, Jews, and Mormons.

${ }^{2}$ Indicator 8 of The Condition of Education 1996, NCES. Between 1992 and 1994, the average enrollment rate in higher education for whites was 9 and 8 percentage points higher than that of blacks and Hispanics, respectively.

${ }^{3}$ The schools students are assigned to according to their residential address.

${ }^{4}$ The county also offers a separate diploma for students with disabilities who attend special education classes.

${ }^{5}$ The District does not publish separate data regarding levels of participation of LEP students in advanced courses. But since the vast majority of language minority students in Dade County is either Hispanic or Black, we can assume that their percentage of participation in advanced courses is at best equal, and probably much smaller, than that of Hispanic and Black students in general. This is the case for both of the schools in this study: very few LEP students were found in advanced level classes.

${ }^{6}$ This larger project has been supported by NSF-cultural Anthropology Grant SBR9511515, the Andrew Mellon Foundation and the Carnegie Corporation.

${ }^{7}$ Dr. Carolyn Herrington, from Florida State University is the co-investigator in the project involved particularly with the educational policy component.

${ }^{8}$ This study focuses on constraints schools face. Of course, structural constraints at the school level (such as lack of funding for specific needs such as hiring bilingual teachers or building new classrooms) do not necessarily constitute structural constraints from the 
point of view of the Board of Education, which decides how and where it spends its money.

${ }^{9}$ The acquisition of the "right" cultural capital, particularly a specific type of linguistic competence, as shown in the work of Basil Bernstein (1975)

${ }^{10}$ This sentence describes what Pierre Bourdieu later would term habitus; recurring patterns of class outlook, inculcated by families and reproduced over time. See Bourdieu (1979)

${ }^{11}$ IQ is usually measured at age 14 , at a time when children can already be reflecting the influence of previous schooling including that of ability grouping. See Hurn (1993)

${ }^{12}$ For a recent example of this type of approach, see Rumberger and Larson (1998).

${ }^{13}$ Although there have been compromises made regarding multicultural add-ons, these do not change the basic fact that History is taught from a basically white European point of view, and does not give equal weight to the perspectives of other peoples. Neither has the notion that there is a core of knowledge that should be required of every student been questioned enough. See Kohl (1994:103-126).

${ }^{14}$ Multicultural education is supposed to decrease interethnic conflict and increase minority achievement by diminishing their sense of alienation from the dominant culture found in the school. Freedman-Lustig (1997) argues that superficial multicultural programs actually exacerbate interethnic conflict.

${ }^{15}$ Such as H.H. Goddard, quoted in Hakuta (1986)

${ }^{16}$ For accounts of these traditions, see Clarence Karier (1976) and Hakuta (1986) 
${ }^{17}$ cf. Clifford Kirkpatrick $\mathrm{K}_{2}$ Intelligence and Immigration, Baltimore: Williams and Wilkins, 1926 quoted in Portes and Rumbaut (1996:198).

${ }^{18}$ Peal and Lambert (1962) quoted in Portes and Schauffler (1996:11).

${ }^{19}$ W.E.Dubois, in a 1925 issue of Crisis, quoted in Kohl (1994). In the 1950's results of the Iowa Standardized Test for a class of black students in a segregated school in the rural south were destroyed because the results exceeded all other scores in the county. Students never received their scores but were told they had scored very well (Ruffin Jr. 1998:22A).

${ }^{20}$ Alfred Binet's test of 'mental age," translated into English by H.H. Goddard, was applied to some two million draftees in World War I, including many foreign born men who were illiterate in English (Portes and Rumbaut 1996).

21 In 1945 Warner and Srole (1945), sociologists who thought assimilation was a linear process, identified three variables affected the speed at which immigrants gain access to a closer interaction with members of the core group. These included race, religion, and language, race being the primary criterion, and non-white groups having the hardest assimilation. Their work however did not deal specifically with education and the younger generation of immigrants.

${ }^{22}$ This is particularly true for math and sciences.

${ }^{23}$ Regular courses can either belong to sequences that are required for college, such as chemistry and physics, or they can belong to sequences that simply fulfill the requirements for graduation, such as environmental science, marine biology, ecology, informal geometry. 
${ }^{24}$ Due to the smaller number of advanced classes offered and the tight gatekeeping that leaves most students out of the more challenging courses.

${ }^{25}$ Even though some say that the brightest students profit from their advanced courses, there are those who believe this to be incorrect because they loose touch with the "real world" of other students.

${ }^{26}$ This is particularly relevant for foreign-born parents who do not know English and even when they do, they may not be familiar with the U.S. tracking system. When information is translated, it is usually in an abbreviated form.

${ }^{27}$ Three questions asked to registering students regarding language spoken at home, first language the child learned, and if anyone at home speaks a language other than English. ${ }^{28}$ Aggregate information for M-DCPS, unless otherwise stated, regards Kindergarten through $12^{\text {th }}$ grade.

${ }^{29}$ Personal communication with ESOL department heads in two of the schools in this project.

${ }^{30}$ In addition to information from the counselors and teachers interviewed, quantitative and qualitative data confirming these high aspirations of students in these schools have been collected in the larger project.

${ }^{31}$ To protect the identity of those involved I have changed the names of neighborhoods, schools, and people.

${ }^{32}$ Source (Miami-Dade County Public Schools 1997d)

${ }^{33}$ Source (Miami-Dade County Public Schools 1997d:9,91) 
${ }^{34}$ This is a result of changes done in the composition of middle schools and senior high schools. The $6^{\text {th }}$ grade, which used to be elementary school, became part of middle schools, together with $7^{\text {th }}$ and $8^{\text {th }}$ grades. $9^{\text {th }}$ graders were transferred from middle schools to senior high schools.

${ }^{35}$ Nationality information is collected on the aggregate level for LEP students and reported to authorized users of the district's data. The general public has access to the District and School Profiles and the Statistical Highlights. Those documents also use the categories I mention here in a non-uniform way.

${ }^{36}$ To find out the nationality of a student, a researcher needs to either interview the student personally or use the emergency cards used by the school, which include country of origin of students. National origin information is not available in any documents with statistics on classroom placement. Aggregate information on national origin is available only for those with authorized access to the county's computer system. This aggregate information is reported to the State and published in the Annual State Report.

${ }^{37}$ During the second semester of the 1997-98 school year, the district changed GPA requirements for graduating students, generating an amount of uncertainty over the graduation prospects of many students whose GPA was between 1.5 and 2.0. For several weeks counselors did not know what to tell these students regarding their graduation prospects.

${ }^{38}$ This larger project has been supported by NSF-cultural Anthropology Grant SBR9511515, the Andrew Mellon Foundation and the Carnegie Corporation. 
${ }^{39}$ Interviews with principals and the Math and English department heads at both schools were conducted by Dr. Carolyn Herrington, from Florida State University and me.

${ }^{40}$ I was able to visit the middle schools while accompanying Dr. Rosa Castro Feinberg, who was then a School Board Member, and who is also a consultant to this project.

${ }^{41}$ TRUST (To Reach Ultimate Success) Counselors deal with students' personal issues particularly regarding drug abuse and teenage pregnancy.

${ }^{42}$ The memorandum was sent to every Chief State School Officer and to the Superintendents of districts with large numbers of language minority students (Castro Feinberg 1990).

${ }^{43}$ For a description of Title VI and other provisions for language minorities, please see Castro Feinberg (1990).

${ }^{44}$ Case \# 90-1913.

${ }^{45}$ META is an acronym for Multicultural Education Training and Advocacy, Inc, a group of lawyers who filed the class action suit of behalf of language minority students. The plaintiffs were a coalition of advocacy groups including LULAC (the League of United Latin American Citizens) who headed the list, followed by Aspira of Florida, the Farmworkers' Association of Central Florida, the Florida State Conference of NAACP Branches, the Haitian Refugee Center, the Spanish American League Against Discrimination (SALAD), the American Hispanic Educator's Association of Dade (AHEAD) and the Haitian Educators' Association. Since LULAC was the first plaintiff mentioned on the list, the agreement is also referred to as "the LULAC consent decree." 
${ }^{46}$ Different provisions exist for elementary schools. Please see Bulletin 1-C (Miami Dade County Public Schools 1995) for information on elementary school provisions. ${ }^{47}$ This means Spanish for Spanish Speakers and Haitian-Creole. The only other group in Dade County that reaches the threshold of 15 students in a school of the same home language is Portuguese speaking students. In the case of other thirteen languages with smaller populations, with twenty or more students in the district, the county provides tutoring once or twice a week (Miami-Dade County Public Schools 1995b).

${ }^{48}$ Although the curriculum bulletin at Northern offered 2 levels and at King offered 4 levels of Haitian-Creole, the roster with all classes taught (Class Sex/Ethnic summary) at each school showed only one level.

${ }^{49}$ Personal communication with Emmanuel Eugene, 6-10-98.

${ }^{50}$ This refers to Haitian students in both schools. At Northern, I was told by the head counselor that they "had the numbers to offer bilingual content (BCC) classes in Spanish also, but did not have the budget."

51 "Grandfathering" granted temporary ESOL endorsement required by the consent decree based on prior experience teaching Basic ESOL. ESOL endorsement attests the teacher can teach English as a second language but does not exempt teachers from fulfilling the META requirements for content area teachers if they also teach other content courses.

52 The Division of Bilingual /Foreign Language Skills and the Office of Educational Accountability do the random selection.

${ }^{53}$ English teachers were required to assign and grade an essay a week per student. 
${ }^{54} \mathrm{An}$ index of movement computed by dividing the number of students, without regard to how many times an individual student enters or withdraws, who have entered or withdrawn from a location during the regular school year by the aggregate number of students in membership at that location during the year.

${ }^{55}$ Requiring parents of LEP students to register students at a central processing point was outlawed, since it imposed an extra burden on LEP parents not imposed on others. ${ }^{56}$ Personal communication with other members of research team: Debbie Teed, Gillian Dawkins, Emmanuel Eugene.

${ }^{57}$ The registrar had a book providing equivalences of courses in most countries and the U.S. If she still had any questions, she could call "downtown," meaning the district offices, and ask for clarification.

${ }^{58}$ The teachers' union (UTD) allows contractual provisions for extra pay for coaches and club sponsors, for example (UTD - D-CPS contract, appendix E, section 5). The contract has no such provisions to allow for extra pay for teachers and counselors to participate in LEP committee meetings after school hours.

${ }^{59}$ The program includes standardized tests such as the Stanford Achievement Test and the Florida Writing Assessment. Another test, the Florida Comprehensive Assessment Test (FCAT, was field tested in 1997, with a baseline administration planned for 1998 . ESOL students are not exempted from the HSCT required for the high school diploma. ${ }^{60}$ Advocates contend it is unfair for LEP students to take longer than the average student to graduate from high school. They are probably right in that it is possible to bring a student performing at elementary or middle school level to high school level in three or 
four years. But in a system already struggling for funding, and in a political climate which is increasingly anti-immigration, the resources, particularly in terms of well trained teachers, and the political will to do that, are difficult to obtain. ${ }^{61}$ Instruction in a foreign language, including Heritage Language Arts, is optional at secondary level. Therefore, there is no guarantee that students enrolled in ESOL are actually exposed to high school level language arts in their native language. Although the consent decree requires accommodation to specific needs of students, and this could be used to override the elective nature of the HLA in secondary schools, this is not the way the decree is interpreted in M-DCPS.

${ }^{62}$ More recently, this has been found to be true also for students from Spanish speaking countries who come from war-torn areas where schooling was not available during long periods as well as for students coming from very remote rural areas with very little educational experience.

${ }^{63}$ This is also true for non-LEP students. But with the difficulties in communication due to language differences and students' lack of knowledge of the details of the educational system, it becomes more damaging.

${ }^{64}$ Counselors have to check for each student whether they have completed all the credits required for graduation, decide with the student if they should take night school classes and enroll them, make sure they completed their community service report and passed both sections of the High School Competency Test.

${ }^{65}$ Although Florida supposedly operates on a $2 \times 2$ plan where High school graduates are expected to go to a community college for the first two years then transfer to a state 
university, this is not the mind set in the schools. The school culture is one where success means going to a four-year college. A community college is a less preferred option.

${ }^{66}$ This is a school level decision that each individual school, usually the principal, makes. Northern is not alone in implementing this rule, which is implemented in other schools in the district as well.

${ }^{67}$ In the $1997-98$ school year, with the addition of a new class of 800 ninth graders to Northern, two more counselors were added: one is an African-American transferred from another school, while the second is Cuban-American and is beginning her career in counseling coming from Social Work.

${ }^{68}$ The school profiles have a chart indicating post secondary plans. The information for the chart comes from an Exit interview all students are required to have before graduation. According to counselors, the numbers in the chart are quite inflated, since very few students will admit they are not continuing their education. Even for students who are actually enrolled in two or four year colleges, counselors say many do not complete their post-secondary education, giving up after a semester or two. They learn this from the students themselves who come to visit, or from siblings or relatives of the graduates who are still in school.

${ }^{69}$ Adeline Becker (1990), when studying Portuguese immigrants in a New England high school found similar perceptions: respect for authority and politeness were appreciated, but also considered as signs of low motivation. 
${ }^{70}$ Students must obtain five points in each grading period, even though they may have enough points to obtain a passing grade in the course. Previously, once a student had enough points to pass, he or she basically could get all F's and get the credit with the minimum passing grade.

${ }^{71}$ Sending all foreign students to a central processing center or creating regional centers specialized in LEP students would be alternatives to processing students in the schools. These alternatives would not make the situation any different unless they were properly staffed with qualified people allowed enough time to perform a reliable assessment. Or, the district could fund a specialist to work with foreign students in schools receiving high numbers of students of the same national origin. Of course, the schools could also choose to do so with their own budget, but it is important to keep in mind that recent arrivals lack the political clout which other groups of students and parents have and use. ${ }^{72}$ Advanced Placement courses, allow students to receive College credit, if they pass the test offered by a private institution. Students enrolled in A.P. courses are entitled to take the exam, at a cost of U\$73,00 each, paid by M-DCPS).

${ }^{73}$ Quantitative data is being collected on national origin from sample of classes from higher and lower tracks at both schools which may support this hypothesis. 


\section{List of References}

Achor, Shirley and Aida Morales. 1990. "Chicanas Holding Doctoral Degrees: Social Reproduction and Cultural Ecological Approaches." Anthropology and Education Quarterly 21:269-285.

Alexander, K., M. Cook, and E. McDill. 1978. "Curriculum Tracking and Educational Stratification." American Sociological Review 43:47-66.

Apple, Michael W. and Louis Weis. 1986. "Seeing Education Relationally: The Stratification of Culture and People in the Sociology of School Knowledge." Journal of Education 168:7-34.

Barr, Rebecca and Robert Dreeben. 1983. How Schools Work. Chicago: University of Chicago.

Becker, Adeline. 1990. "The Role of the School in the Maintenance and Change of Ethnic Group Affiliation." Human Organization 49:48-55.

Bernstein, Basil. 1975. Class, Codes and Control, vol. 3. London: Routledge and Keagan Paul.

Block, N.J. and Gerald Dworkin. 1976. The I.Q. Controversy. New York: Random House.

Bourdieu, Pierre. 1979. Outline of a Theory of Practice. Cambridge, U.K.: Cambridge University Press.

Bourdieu, Pierre and J.C. Passeron. 1977. Reproduction in Education, Society and Culture: Sage Publications.

Bowles, S. and H. Gintis. 1976. Schooling in Capitalist America: Educational Reform and the Contradictions of Economic Life. N.Y.: Basic Books, Inc. 
Brint, Steven. 1998. Schools and Societies, Edited by C. Ragin. London: Sage Publications Ltd.

Carey, Nancy, Laurie Lewis, and Elizabeth Farris. 1998. "Parental Involvement in Children's Education: Efforts by Public Elementary Schools." National Center for Education Statistics.

Castro Feinberg, Rosa. 1990. "Bilingual Education in the United States: A Summary of Lau Compliance Requirements." Journal of Language, Culture and Curriculum 3:141-152.

Cole, Michael. 1988. Bowles and Gintis Revisited: Correspondence and Contradiction in Educational Theory. London: Falmer Press.

Collins, Randall. 1979. The Credential Society. New York: Academic Press.

Cooper, Robert. 1996. "Detracking Reform in an Urban California High School: Improving the Schooling of African American Students." Journal of Negro Education 65:190-208.

Datnow, Amanda. 1997. "Gender as a Defensive Strategy." Anthropology and Education Quarterly 28:204-228.

DeVos, George. 1980. "Ethnic Adaptation and Minority Status." Journal of Cross Cultural Psychology 11:101-124.

Eisikovits, Rivka. 1997. "The Educational Experience and Performance of Immigrant and Minority Students in Israel." Anthropology and Education Quarterly 28:394410.

Eldering, Lotty. 1997. "Ethnic Minority Students in the Netherlands from a CulturalEcological Perspective.” Anthropology and Education Quarterly 28:330-350. 
Finley, Merilee K. 1984. "Teachers and Tracking in a Comprehensive High School." Sociology of Education 57:233-243.

Fjellman, Stephen M. 1992. Vinyl Leaves. Walt Disney World and America. Boulder, CO: Westview Press, Inc.

Fleischman, H.L. and P. J. Hopstock. 1993. "Descriptive Study of Services to Limited English Proficient Students." Report to the U.S. Department of Education, Office of the Undersecretary. Development Associates, Inc., Arlington, VA.

Freedman Lustig, D. 1997. "Of Kwanzaa, Cinco de Mayo, and Whispering: The Need for Intercultural Education." Anthropology and Education Quarterly 28:574-592.

Gamoran, Adam. 1987. "The Stratification of High School Learning Opportunities." Sociology of Education 60:135-55.

Gamoran, Adam and Mark Berends. 1987. "The Effects of Stratification in Secondary Schools: Synthesis of Survey and Ethnographic Research." Review of Educational Research 57:415-35.

Gibson, Margaret A. 1997. "Exploring and Explaining the Variability: Cross-National Perspectives on the School Performance of Minority Students." Anthropology and Education Quarterly 28:318-329.

Gibson, Margaret A. and John U. Ogbu. 1991. "Minority Status and Schooling: A Comparative Study of Immigrant and Involuntary Minorities." in Garland reference library of social science, vol. 618 , edited by M. A. Gibson and J. U. Ogbu. New York: Garland.

Gottfredson, Denise C. 1981. "Black -White Differences in the Educational Attainment Process: What Have We Learned?" American Sociological Review 46:542-557. 
Hakuta, Kenji. 1986. Mirror of Language: the Debate on Bilingualism. New York: Basic Books.

Hallinan, Maureen T. 1994. "Tracking: From Theory to Practice." Sociology of Education 67:79-84.

Hurn, Christopher J. 1993. The Limits and Possibilities of Schooling: An Introduction to the Sociology of Education. Boston: Allyn and Bacon.

Jencks, Christopher and et al. 1979. Who Gets Ahead? New York: Basic Books.

Kalmijn, Matthijs and Gerbert Kraaykamp. 1996. "Race, Cultural Capital, and Schooling: An Analysis of Trends in the United States." Sociology of Education 69:22-34

Kao, Grace and Marta Tienda. 1995. "Optimism and Achievement: The Educational Performance of Immigrant American Youth.” Social Science Quarterly 76:1-19.

Karabel, Jerome and A.H. Halsey. 1977. "Educational Research: A Review and An Interpretation." Pp. 1-85 in Power and Ideology in Education, edited by J.

Karabel and A. H. Halsey. N.Y.: Oxford University Press.

Karier, Clarence J. 1976. Shaping the American Educational State: 1900 to the present. New York: Free Press.

Kelly, D. 1975. "Tracking and Its Impact on Self-estem: A Neglected Dimension." Education 96.

Kohl, H. 1994. I Won't Learn from You and Other Thoughts on Creative Maladjustment: The New Press.

Lazerson, M. 1974. Origins of the Urban School. Cambridge: Harvard University Press. 
LULAC et. al. v. Florida Board of Education and Florida Department of Education. 1990. in 90-1913 Civ. Scott. S.D. Fla.: Miami Division.

McDermott, Ray P. 1977. "Social Relations as Contexts for Learning." Harvard Educational Review 47:198-213.

McDermott, Raymond P. 1987. "Making Dropouts." Pp. 16-26 in What do Anthropologists Have to Say About Dropouts? The First Centennial Conference on Children at Risk, edited by H. T. Trueba, G. Spindler, and L. Spindler. University of California at Santa Barbara: The Falmer Press.

McLaren, Peter. 1998. Life in Schools. An Introduction to Critical Pedagogy in the Foundations of Education. New York: Longman.

Mehan, Hugh, Lea Hubbard, Angela Lintz, and Irene Villanueva. 1994. “Tracking Untracking: The Consequences of Placing Low Track Students in High Track Classes." University of California, San Diego.

Miami -Dade County Public Schools. 1995. "Procedures Manual Bilingual/Foreign Language Education." in Bulletin 1-C. Miami, Florida: Division of Bilingual/Foreign Language Skills,

Miami-Dade County Public Schools. 1995a. "Comprehensive Student Services Program.

PK- Adult." in Board Rule 6Gx13-5D-1.091. Miami, Florida: Division of Student Services and Attendance,

Miami-Dade County Public Schools. 1995b. "District Plan for Limited English Proficient Students, 1995-1998.”. Miami, Florida: Office of Instructional Leadership, 
Miami-Dade County Public Schools. 1996a. "District and School Profiles 1995-96.".

Miami, Florida: Office of Educational Accountability,

Miami-Dade County Public Schools. 1996b. "Pupil Progression Plan.” Miami, Florida:

Office of Instructional Leadership,

Miami-Dade County Public Schools. 1997a. "Curriculum Bulletin School Year 19971998.". Miami, Florida.

Miami-Dade County Public Schools. 1997b. "Dade County School Board Rules. 6Gx136A-1.46." in Magnet Programs/Schools. Miami, Florida.

Miami-Dade County Public Schools. 1997c. "District and School Profiles 1996-97.".

Miami, Florida: Office of Educational Accountability,

Miami-Dade County Public Schools. 1997d. "Statistical Abstract 1996-97.". Miami,

Florida: Management and Accountability, Department of Management Analysis,.

Miami-Dade County Public Schools. 1997e. "Telecourse Calendar for Teachers of

Limited English Proficient Students (META Training)." in Memorandum NSC

1996-97¥069. Miami, Florida: Division of Bilingual/Foreign Language Skills,.

Miami-Dade County Public Schools. 1998a. “About META.” . Miami, Florida:

Personnel Management and Services.

Miami-Dade County Public Schools. 1998b. "Statistical Highlights, 1997-98." . Miami,

Florida: Office of Educational Accountability.

Mosca, Gaetano. 1939. The Ruling Class. N.Y: McGraw Hill.

National Center for Education Statistics. 1996a. "The 1994 High School Transcript

Tabulations: Comparative Data on Credits Earned and Demographics for 1994, 
1990, 1987 and 1982 High School Graduates." U.S. Department of Education, Washington, D.C.

National Center for Education Statistics. 1996b. "The Condition of Education." U.S. Department of Education, Washington, DC.

Oakes, Jeannie. 1982. "The Reproduction of Inequity: The Content of Secondary School Tracking." Urban Review 14:107-120.

Oakes, Jeannie. 1983. "Tracking and Ability Grouping in American Schools: Some Constitutional Questions." Teachers College Record 84:801-819.

Oakes, Jeannie. 1985. Keeping Track: How Schools Structure Inequality. New Haven, CT: Yale University Press.

Oakes, Jeannie. 1986. "Tracking Inequality, and the Rhetoric of Reform: Why Schools Don't Change." Journal of Education 168:60-80.

Oakes, Jeannie. 1990. "Multiplying Inequalities: The Effects of Race, Social Class, and Tracking on Opportunities to Learn Math and Science.". Santa Monica, CA: Rand Corporation.

Oakes, Jeannie. 1994. "More than Misapplied Technology: A Normative and Political Response to Hallinan on Tracking." Sociology of Education 67:84-89.

Oakes, Jeannie. 1995. "Two Cities' Tracking and Within-School Segregation." Teachers College Record 96:681-690.

Office of Bilingual Education and Minority Language Affairs. 1997. “About Us!”. http://www.ed.gov/offices/OBEMLA/aboutus.html. 
Office of Multicultural Student Language Education. 1995. "Multicultural Student Language Education : the Consent Decree, History and Background.".

Tallahassee: Florida Department of Education.

Ogbu, John U. 1974. The Next Generation: An Ethnography of Education in an Urban Neighborhood. New York: Academic Press.

Ogbu, John U. 1987. "Variability in Minority School Performance: A Problem in Search of an Explanation." Anthropology and Education Quarterly 18:312-334.

Ogbu, John U. 1990. "Minority Education in Comparative Perspective." Journal of Negro Education 59:45-57.

Pallas, Aaron M., Doris R. Entwisle, Karl L. Alexander, and M. Francis Stluka. 1994. "Ability-Group Effects: Instructional, Social or Institutional?" Sociology of Education 67:27-46.

Peal, Elizabeth and Wallace E. Lambert. 1962. "The Relation of Bilingualism to Intelligence." Psychological Monographs: General and Applied 76:1-23. Portes, Alejandro. 1995. "Segmented Assimilation among New Immigrant Youth: A Conceptual Framework." Pp. 71-76 in California's Immigrant Children:Theory, Research, and Implications for Educational Policy, edited by R. G. Rumbaut and W. A. Cornelius. San Diego: La Jolla: Center for U.S.-Mexican Studies, University of California.

Portes, Alejandro and Ruben G. Rumbaut. 1996. Immigrant America: A Portrait. Berkeley, California: University of California Press. 
Portes, Alejandro and Richard Schauffler. 1996. "Language and the Second Generation: Bilingualism Yesterday and Today." Pp. 8-29 in The New Second Generation, edited by A. Portes. New York: Russel Sage Foundation.

Pottinger, J.S. 1970. "Memorandum to School Districts With MoreThan Five Percent National Origin Minority Group Children Regarding Identification of Discrimination and Denial of Services on the Basis of National Origin.”. 35 Federal Register 11595: Department of Health, Education, and Welfare.

Resnick, Daniel P. and Lawrence B. Resnick. 1985. "Standards, Curriculum and Performance: A Historical and Comparative Perspective." Educational Researcher 14:5-20.

Riordan, Cornelius. 1997. Equality and Achievement: An Introduction to the Sociology of Education. New York: Addison-Wesley.

Rist, Ray. 1970. "Social Class and Teacher Expectations: The Self-Fulfilling Prophecy in Ghetto Education." Harvard Educational Review 40:411-451.

Rosenbaum, J. 1976. Making Inequality: The Hidden Curriculum of High School Tracking. New York: Wiley.

Rosenthal, Robert and Lenore Jacobsen. 1968. Pygmalion in the Classroom. New York: Holt, Rinehart and Winston.

Ruffin Jr., John. 1998. "I Can Sing You a Song of Trial and Triumph." Pp. 22A in The Miami Herald. Miami, Fl.

Rumbaut, Ruben G. 1995. "The New Californians: Comparative Research Findings on the Educational Progress of Immigrant Children." in California's Immigrant Children: Theory, Research, and Implications for Educational Policy, edited by 
R. G. Rumbaut and W. A.Cornelius. San Diego: La Jolla: Center for U.S.Mexican Studies, University of California.

Rumbaut, Ruben G. 1996. “The Crucible Within; Ethnic Identity, Self-Esteem, and Segmented Assimilation Among Children of Immigrants." Pp. 119-170 in The New Second Generation, edited by A. Portes. New York: Russell Sage Foundation.

Rumberger, Russel W. and Katherine A. Larson. 1998. "Toward Explaining Differences in Educational Achievement among Mexican American Language-Minority Students." Sociology of Education 71:68-93.

Saha, Lawrence J. 1987. “Social Mobility versus Social Reproduction: Paradigms and Politics in the Sociology of Education." New Education 9:14-28.

Sapon-Shevin, Mara. 1993. "Gifted Education and the Protection of Privilege: Breaking the Silence, Opening the Discourse." in Beyond Silenced Voices. Class, Race, and Gender in United States Schools, edited by L. Weis and M. Fine. New York: State University of New York Press.

Seller, M. and L. Weiss. 1997. "Beyond Black and White: New Voices in U.S. Schools." in Power, Social Identity and Education, edited by S. Series. N.Y.: State University of New York Press.

Spindler, George. 1955. Education and Anthropology. Stanford,CA: Stanford University Press.

Spindler, Geoge and Louise. 1987. "There Are No Dropouts among the Arunta and Hutterites." in What do Anthropologists Have to Say About Dropouts? The First 
Centennial Conference on Children at Risk, edited by H. T. Trueba, G. Spindler, and L. Spindler. University of California, Santa Barbara: The Falmer Press.

Steinberg, Laurence, B. Bradford Brown, and Sanford M. Dornbusch. 1996. Beyond the Classroom: Why School Reform Has Failed And What Parents Need To Do. N.Y.: Simon and Schuster.

Stepick, Alex. 1995. "The Academic Orientation of Minority Adolescents." in Prospectus of Research Proposal Funded by the National Science Foundation.

Stevenson, D.L., K.S. Schiller, and B. Schneider. 1994. "Sequences of Opportunities for Learning." Sociology of Education 67:184-198.

Suarez-Orozco, Marcelo. 1987. "Becoming Somebody: Central American Immigrants in U.S. Inner -City Schools." Anthropology and Education Quarterly 18:287-299. Suarez-Orozco, Marcelo. 1989a. "Psychosocial Aspects of Achievement Motivation among Recent Hispanic Immigrants." Pp. 99-116 in What do Anthropologists Have to Say About Dropouts?, edited by H. T. Trueba, G. Spindler, and L. Spindler. New York: The Falmer Press.

Suarez-Orozco, Marcelo M. 1989b. Central American Refugees and U.S. High Schools: A Psychosocial Study of Motivation and Achievement. Stanford: Stanford University.

Trueba, Henry T. 1987a. "The Ethnography of Schooling." Pp. 1-13 in Success or Failure: Linguistic Minority Children at Home and in School. New York: Haper and Row.

Trueba, Henry T. 1987b. "Rethinking Dropouts: Culture and Literacy for Minority Student Empowerment." Pp. 27-42 in What do Anthropologists Have to Say 
About Dropouts? The First Centennial Conference on Children at Risk, edited by

H. T. Trueba, G. Spindler, and L. Spindler. University of California, Santa Barbara: The Falmer Press.

Trueba, Henry T. 1988. "Culturally Based Explanations on Minority Students' Academic Achievement." Anthropology and Education Quarterly 19:270-285.

Trueba, Henry T., L. Cheng, and K. Ima. 1992. "Myth or Reality: Adaptive Strategies of Asian Americans in California.". London: Falmer Press.

van Zantan, Agnes. 1997. "Schooling Immigrants in France in the 1990s: Success or Failure of the Republican Model of Integration?" Anthropology and Education Quarterly 28:351-374.

Warner, W. Lloyd and Leo Srole. 1945. The Social Systems of American Ethnic Groups. Westport, Connecticut: Greenwood Press.

Weber, Max. 1946. From Max Weber: Essays in Sociology, Edited by H. Gerth and C. W. Mills. Translated by H.H. Gerth and C. Wright Mills. New York: Oxford University Press.

Wells, Amy Stuart and Jeannie Oakes. 1996. "Potential Pitfalls of Systemic Reform: Early Lessons from Research on Detracking." Sociology of Education :135-143. Willis, Paul. 1981. Learning to Labor: How Working Class Kids Get Working Class Jobs. New York: Columbia University Press.

Zehler, A.N., Paul J. Hopstock, Howard L Fleischman, and Cheryl Greniuk. 1994. "An Examination of Assessment of Limited English Proficiency Students.” Special Issues Analysis Center Development Associates, Inc, Arlington, VA. 
Appendix 1 


\section{7-1998 COURSE REQUIREMENTS}

The following chart compares high school graduation, Florida state universities, Florida Academic Scholars Certificate Program, and Florida Gold Seal Endorsement course requirements for 1997-98.

\begin{tabular}{|c|c|c|c|c|}
\hline SUBJIXCTS & $\begin{array}{l}\text { HIGH } \\
\text { SCHOOL } \\
\text { GRAD }\end{array}$ & $\begin{array}{l}\text { FLA. STATE } \\
\text { UNIVERSITIXS } \\
\text { MININIUNI } \\
\text { REQUIRENIENTS } \\
\text { FOR ENTRANCE }\end{array}$ & $\begin{array}{l}\text { FLORIDA } \\
\text { ACADENIC } \\
\text { SCHOLARS } \\
\text { CERT }\end{array}$ & $\begin{array}{l}\text { FLORIDA GOLD } \\
\text { SEAL } \\
\text { ENDORSTSIENT }\end{array}$ \\
\hline LANGUAGE ARTS & $4(\mathrm{~A})$ & $4(B)$ & $4(A)(B)$ & $4(A)$ \\
\hline MATHEMATICS & $3(\mathrm{C})$ & $3(\mathrm{D})$ & $4(E)$ & $3(C)$ \\
\hline SCIENCE & $3(F)$ & $3(G)$ & $4(\mathrm{H})$ & 3 \\
\hline SOCIAL SCIENCE & $3(\mathrm{I})$ & $3(\mathrm{~J})$ & $3(I)$ & $3(\mathrm{I})$ \\
\hline FOREIGN LANG & & $2(\mathrm{~K})$ & $2(\mathrm{~L})$ & \\
\hline $\begin{array}{c}\text { FINE AND } \\
\text { PERFORMING ARTS }\end{array}$ & $.5(\mathrm{M})$ & & $1(N)$ & $.5(\mathrm{M})$ \\
\hline PRACTICAL ARTS & $.5(0)$ & & & $.5(0)$ \\
\hline HEALTH/LIFE MGT & $.5(\mathrm{P})$ & & .5 & $.5(\mathrm{P})$ \\
\hline PERSONAL FITNESS & .5 & & .5 & .5 \\
\hline APPROVED ELECT. & & $4(Q)$ & & \\
\hline GENERAL ELECT. & $9(R)$ & & 5 & 0.6 \\
\hline $\begin{array}{l}\text { APPLIED TECH. } \\
\text { (VOCATIONAL) }\end{array}$ & & & & $3-9(S)$ \\
\hline TOTALS & 24 & 19 & 24 & 24 \\
\hline
\end{tabular}

(Letters in parentheses refer to notes starting below)

A. ESOL I, II, III, and IV may be used to meet the language arts requirement. Additional ESOL credit may be counted as elective credit.

B. Three of which must have included substantial writing requirements 
C. Three credits must be earned in grades $9,10,11$, one of which must be Algebra I (regular or honors) for students who entered grade 9 in 1994-95, students should successfully complete the Algebra I requirement by the end of grade nine.

D. At the Algebra I and above levels, excluding Informal Geometry and Liberal Arts Mathematics

E. To include one algebra or integrated mathematics course, one geometry or integrated mathematics course, \& one trigunumitry or calculus course, excluding informal geometry and liberal arts mathematic:

F. One of the three credits earned in science must be Physical Science (regular or honors), or Hutcigted Science 1. Two of the science credits must include a laboratory component. Biology or lintegrated Science II is the next course in the recommended science sequence for students who entered grade 9 in 1996-97 to be followed by Chemistry, Physics, or Integrated Science III.

G. Two of which must have included a substantial laboratory component.

H. To include one biology, one chemistry, and one physics credit or Integrated Science I-V

I. To include one credit in American history, one credit in world history, one-half credit in economics, and one-half credit in American government

J. To include study related to history, civics, political science, economics, sociology, psychology, and geography

K. Any two sequential courses in the same language, including American sign language, or mastery as demonstrated through testing

L. Any two sequential credits in the same language with the exception of courses labeled conversational

M. Any art, dance, drama, music, speech, or debate course classified as performing fine arts (performing and visual arts)

N. One-half credit in any performing fine arts (performing and visual arts) course in art, dance, drama, music, speech, debate, and one-half credit in any fine arts elective; i.e., art, dance, drama, music, speech, or debate

O. Any applied technology (vocational) course or Journalism II, III, or IV

P. The life management course must be tak. .1 in grades 9 or 10 .

Q. Includes courses in English, mathematics, foreign language, science, social science, humanities, computer education, up to two credits in fine arts, up to one credit in health/life management and physical education, up to two credits in vocational education, up to one credit in executive internship, up to one credit in leadership skills, up to one credit in research, and any dual enrollment courses

R. Any course listed in the current State Course Code Directory which is appropriate for grade 9 or above may fulfill an elective credit for graduation except Study Hall and other courses identified as noncredit (NC), Adult Basic Education, and GED preparation. In selecting their electuve, students are encouraged to focus on a special interest or a career goal.

S. A minimum of three credits in a sequential program of study in an applied technology (vocational) program.

NOTE: Students who satisfactorily complete selected applied technology (vocitional) jub preparatory programs may substitute one or more of the following courses for a required langudte ants, mathematics, or science course: Business English I, Business English 1I, Business Misthematics, General Science, and Anatomy and Physiology. 


\section{HIGH SCHOOL DIPLOMAS/CERTIFICATES}

The Dade County School Board provides for the awarding of a standard diploma, a certificate of completion, a special diploma, or a special certificate of completion.

\section{STANDARD DIPLOMA}

A standard diploma will be awarded to graduates in 1997.98 , if the student has earned 24 credits for graduation in grades $9-12$ with a cumulative unweighted grade point average of 1.5 . Credits must have been earned in all required courses. Also, students must meet the minimum performance standards and pass the High School Competency Test (HSCT). The purpose of the stanuard diploma is to certify that the student has met all local and state standards for graduation. An exceptional education student will be awarded a standard diploma if all of the criteria for a standard diploma have been met by that student. Note: Students who entered grade 9 in 1996-97 are required to earn a cumulative unweighted grade point average of 2.0 .

\section{SUPERINTENDENT'S DIPLOMA OF DISTINCTION}

Beginning with students who entered ninth grade in 1993-94, this diploma will be awarded to students who complete an academically rigorous course of study. The requirements include at least four honors, Advanced Placement, and/or International Baccalaureate courses; and completion of 75 hours of community service, which includes identification of a social problem of interest, development of a plan for personal involvement in addressing the problem and, through papers and other presentations, evaluate, and reflect upon the experience. All students must earn a 3.5 GPA (weighted scale) with no final grade less than a "C."

\section{CERTIFICATE OF COMPLETION}

A student who has met all requirements for graduation except passing the HSCT; mastering the minimum student performance standards; and/or eaming a cumulative, unweighted grade point average of 1.5 , as set forth by the State Board of Education, shall be awc ded a certificate of completion. NOTE: Students who entered grade 9 in 1996-97 are required to eam a cumulative unweighted grade point average of 2.0 .

\section{SPECIAL DIPLOMA AND SPECIAL CERTIFICATE OF COMPLETION}

Exceptional students who have been properly classified may be eligible to receive a special diploma or a special certificate of completion. Parents who have questions concerning these special diplomas or certificates are urged to consult the school counselor, exceptional student education department chairperson, or Region exceptional student education staffing specialist. 
Appendix 2 


\section{ENROLLMENT IN ADVANCED LEVEL COURSES:}

The following is a summary of participation in advanced level courses during the last four years. This analysis shows that the participation in the advanced level courses by students in the various ethnic/gender categories has increased over the past four years.

\section{PARTICIPATION IN ADVANCED LEVEL COURSES} (AS PERCENT OF TOTAL 9-12 STUDENT PERIODS)*

\begin{tabular}{lcccc}
\hline & $\begin{array}{c}1993-94 \\
\text { (As of } \\
10 / 8 / 93)\end{array}$ & $\begin{array}{c}1994-95 \\
\text { (As of } \\
10 / 8 / 94)\end{array}$ & $\begin{array}{c}1995-96 \\
\text { (As of } \\
10 / 8 / 95)\end{array}$ & $\begin{array}{c}1996-97 \\
\text { (As of } \\
10 / 8 / 96)\end{array}$ \\
\hline Black & $9.6 \%$ & $9.8 \%$ & $10.1 \%$ & $11.0 \%$ \\
White & 26.8 & 27.6 & 29.9 & 32.0 \\
Hispanic & 11.4 & 12.0 & 13.1 & 14.7 \\
Asian/Other** & 32.4 & 36.4 & 38.9 & 41.8 \\
Total Male & 14.4 & 11.1 & 11.7 & 12.9 \\
Total Female & 16.7 & 17.0 & 18.3 & 19.8 \\
Districtwide Total & 13.6 & 14.0 & 15.0 & 16.3 \\
\hline
\end{tabular}

\section{Participation in Advanced Level Courses}

As Percent of Total 9-12 Student Periods*

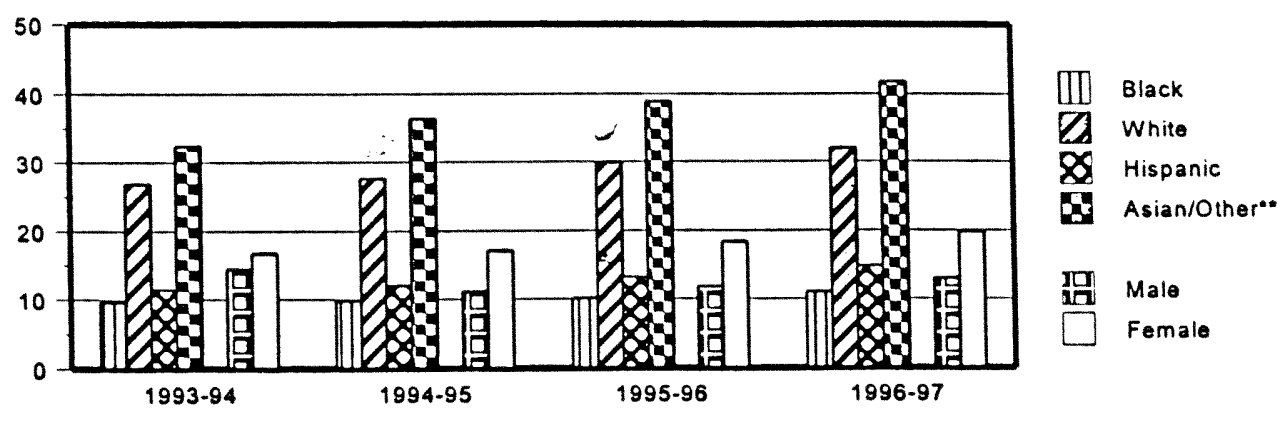

- Total student periods were computed by multiplying total student membership in grades 9-12 in each of the ethnic/ gender categories by six. The percentage has been computed by dividing total enrollment in advanced courses by total student periods.

*. Includes American Indian and Multiracial (data for 1993-94 to 1995-96 applicable to Asians only).

Source: ISIS CB-I Course Files, compiled by Office of Educational Planning. 